\title{
Phosphoinositide-3-Kinase Activation Controls Synaptogenesis and Spinogenesis in Hippocampal Neurons
}

\author{
Germán Cuesto, ${ }^{1,2}$ Lilian Enriquez-Barreto, ${ }^{1}$ Cristina Caramés, ${ }^{2}$ Marta Cantarero, ${ }^{2}$ Xavier Gasull, ${ }^{2}$ Carmen Sandi, ${ }^{3}$ \\ Alberto Ferrús, ${ }^{4}$ Ángel Acebes, ${ }^{4}$ and Miguel Morales ${ }^{1}$ \\ ${ }^{1}$ Structural Synaptic Plasticity Lab, Department of Neurodegenerative Diseases, Centro de Investigación Biomédica de la Rioja, La Rioja 26006, Spain, \\ ${ }^{2}$ Neurophysiology Lab, Department of Physiology, Medical School, University of Barcelona, Barcelona 08036, Spain, ${ }^{3}$ Brain Mind Institute, École \\ Polytechnique Fédérale de Lausanne, Lausanne, CH-1015 Switzerland, and ${ }^{4}$ Department of Cellular, Molecular and Developmental Neurobiology, Cajal \\ Institute, Consejo Superior de Investigaciones Científicas, Madrid 28002, Spain
}

The possibility of changing the number of synapses may be an important asset in the treatment of neurological diseases. In this context, the synaptogenic role of the phosphoinositide-3-kinase (PI3K) signaling cascade has been previously demonstrated in Drosophila. This study shows that treatment with a PI3K-activating transduction peptide is able to promote synaptogenesis and spinogenesis in primary cultures of rat hippocampal neurons, as well as in CA1 hippocampal neurons in vivo. In culture, the peptide increases synapse density independently of cell density, culture age, dendritic complexity, or synapse type. The induced synapses also increase neurotransmitter release from cultured neurons. The synaptogenic signaling pathway includes PI3K-Akt. Furthermore, the treatment is effective on adult neurons, where it induces spinogenesis and enhances the cognitive behavior of treated animals in a fear-conditioning assay. These findings demonstrate that functional synaptogenesis can be induced in mature mammalian brains through PI3K activation.

\section{Introduction}

In mammals, class IA phosphoinositide-3-kinase (PI3K) is a heterodimer formed by a $110 \mathrm{kDa}$ catalytic subunit $(\mathrm{p} 110 \alpha, \mathrm{p} 110 \beta$, or $\mathrm{p} 110 \delta)$ and a smaller regulatory subunit $(\mathrm{p} 85 \alpha,-\beta$, and $-\gamma$, $\mathrm{p} 55 \alpha$, and $\mathrm{p} 50 \alpha$ ) (Wymann and Pirola, 1998). The p 85 subunit binds, stabilizes, and inhibits p110 activity (Yu et al., 1998). Following the activation of a tyrosine kinase receptor, the p85-p110 complex is recruited to the receptor alleviating p110 inhibition, leading to the production of phosphatidylinositol 3,4,5-trisphosphate $\left(\mathrm{PIP}_{3}\right)$ from phosphatidylinositol 4,5-bisphosphate $\left(\mathrm{PIP}_{2}\right)$ (Vanhaesebroeck et al., 2001). PIP ${ }_{3}$ acts as second messenger by recruiting to the membrane and activating the Akt kinase, which in turn results in the phosphorylation of downstream targets, including glycogen synthase kinase 3 (GSK3) and mammalian target of rapamycin (mTOR) (Ruggero and Sonenberg, 2005).

In neurons, the PI3K pathway controls a variety of neuronal responses. In addition to its role in neuronal survival (Brunet et

Received Aug. 26, 2010; revised Sept. 24, 2010; accepted Sept. 27, 2010.

This research was funded by grants from Fundación Areces (A.A. and M.M.); Fundación Reina Sofía (A.F., M.M., and A.A.), Grant BFU2009-12410/BMC (A.F.); the European Union FP7-Health Consortium MemStick (C.S.) and the Swiss National Science Foundation 310000-120791 (C.S.); and Fundacion Rioja Salud, Spain (M.M.). We thank Jocelyn Grosse for his help and advice with the behavior experiments and Dr. Imanol Martinez Padron for his critical reading. We thank Anna Bosch and Dr. Maria Calvo from the Confocal-Microscopy Facility [Unitat de Serveis Cientificotècnics; Facultat de Medicina (UB-IDIBAPS)] for their support and advice with all confocal microscopy techniques.

Correspondence should be addressed to either of the following: Ángel Acebes, Department of Cellular, Molecular and Developmental Neurobiology, Cajal Institute, Consejo Superior de Investigaciones Científicas, Dr Arce 37, 28002 Madrid, Spain, E-mail: a.acebes@cajal.csic.es; or Miguel Morales, Structural Synaptic Plasticity Laboratory, Department of Neurodegenerative Diseases, CIBIR, Piqueras 98, 26006, Logroño, La Rioja, Spain, E-mail:miguel.morales@ riojasalud.es.

DOI:10.1523/JNEUROSCI.4477-10.2011

Copyright $\odot 2011$ the authors $\quad 0270-6474 / 11 / 312721-13 \$ 15.00 / 0$ al., 2001), PI3K has been implicated in dendritic morphogenesis (Jaworski and Sheng, 2006), neuronal polarity and growth (Jiang and Rao, 2005), synaptic plasticity (Opazo et al., 2003), memory formation (Lin et al., 2001), and AMPA receptors clustering at the postsynaptic density (Arendt et al., 2010). Conversely, alterations in the Akt pathway are important features in several neurodegenerative diseases, including Huntington's disease (Humbert et al., 2002) and Alzheimer's disease (Griffin et al., 2005).

In Drosophila, overexpression of the catalytic subunit Dp110 (homolog to human p110) increases the number of functional synapses in larval and adult fly neurons, independently of cell size or proliferation (Martín-Peña et al., 2006). The actual PI3Kdependent synaptogenic pathway also involves Akt-GSK3 signaling; thus, overexpression of Akt results in a synaptic increase similar to that produced by Dp110, and overexpression of GSK3 reduces the number of synapses, while GSK3 downregulation increases axonal growth and synaptic terminals (Franco et al., 2004; Martín-Peña et al., 2006).

In mammalian neurons, there is some evidence suggesting that the PI3K/Akt/GSK3 pathway plays a role in synaptogenesis and spinogenesis. Thus, the selective elimination of phosphatase and tensin homolog (PTEN), a lipid phosphatase that dephosphorylates $\mathrm{PIP}_{3}$ and reverses PI3K activation, causes Akt overactivation, resulting in dendritic hypertrophy, increased spine density, and, finally, macrocephaly (Kwon et al., 2006). Moreover, GSK3 activity has been implicated in axon formation, given that constitutively active mutants inhibit this formation, whereas loss-of-function mutants promote the formation of multiple axons (Jiang et al., 2005; Yoshimura et al., 2006). Furthermore, mTOR and S6 kinase (S6K), downstream components of the 
PI3K/Akt pathway, are present in the synapse and have been shown to mediate synaptic plasticity and dendritic elongation (Tang et al., 2002; Tsokas et al., 2005).

In the present study, using a peptide mimetic of the pTyr domain of the PDGF receptor to increase PI3K activation (Derossi et al., 1998), we show that PI3K activation induces synaptogenic and spinogenic effects on primary cultures of rat hippocampal neurons and also on CA1 hippocampal neurons in vivo. Furthermore, these morphological changes are functional according to the criteria of increased basal neurotransmitter release, and correlate with an enhancement of cognitive behavior in the treated animals. These data provide proof of the notion that synaptogenesis can be induced in mammals through PI3K activation.

\section{Materials and Methods}

\section{Cell cultures}

Primary cultures of hippocampal neurons were prepared from postnatal [postnatal day (P) 0-P1] rat pups, as previously described (Banker and Goslin, 1998; Morales et al., 2000). Glass coverslips (12 mm in diameter) were coated with poly-L-lysine $(100 \mu \mathrm{g} / \mathrm{ml})$ and laminin $(4 \mu \mathrm{g} / \mathrm{ml})$. In brief, hippocampal neurons were seeded at $15 \times 10^{4} / \mathrm{cm}^{2}$ in a culture medium consisting of Neurobasal medium (Invitrogen) supplemented with glutamine $0.5 \mathrm{mM}, 50 \mathrm{mg} / \mathrm{ml}$ penicillin, $50 \mathrm{U} / \mathrm{ml}$ streptomycin, $4 \%$ FBS, and 4\% B27 supplement (Invitrogen). After 4, 7, 14, and $21 \mathrm{~d}$ in culture, $100 \mu \mathrm{l}$ (of a total of $500 \mu \mathrm{l}$ ) of culture medium was replaced by $120 \mu \mathrm{l}$ of fresh medium. On day 4, $4 \mu \mathrm{M}$ cytosine-D-arabinofuranoside was added to prevent overgrowth of glial cells.

\section{Transfection}

Electroporation before plating was performed using the kit from AMAXA. To this end, $\sim 2 \times 10^{6}$ cells were mixed with $10 \mu \mathrm{g}$ of plasmid and then electroporated, following the manufacturer's instructions. Two expression vectors were used: an empty vector cytomegalovirus (CMV)enhanced green fluorescent protein (eGFP)-N1 (Clontech) and a vector plasmid encoding the GFP protein chimeric with the $\mathrm{N}$ terminus of chick $\beta$-actin under the control of the platelet-derived growth factor enhancer/ promoter region (kindly provided by Y. Goda, MRC Cell Biology Unit, University College London, London, UK) (Colicos et al., 2001).

\section{PI3K-activating peptides}

Control activation of PI3K activity was achieved by using a peptide named PTD4-PI3KAc, which consists of a transduction domain, PTD4 [Tyr-Ala-Arg-Ala-Ala-Ala-Arg-Gln-Ala-Arg-Ala (Ho et al., 2001)], fused to a phosphopeptide containing the intracellular phosphorylated domain of the PDGF receptor C terminus [Gly-Ser-Asp-Gly-Gly-pTyrMet-Asp-Met-Ser (Derossi et al., 1998)]. A series of peptides containing only the PTD4 transduction domain by itself or fused to rhodamine or FITC were used as controls. All peptides were purchased from GenScript.

\section{Immunocytochemistry and image analysis}

Immunocytochemical analysis was performed on hippocampal neuronal cultures from 1 to 3 weeks in vitro. Cultures were rinsed in PBS and fixed for $30 \mathrm{~min}$ in $4 \%$ paraformaldehyde in PBS. Coverslips were washed three times in PBS and incubated for $30 \mathrm{~min}$ in blocking solution $(2 \%$ goat serum, $2 \%$ serum albumin, $0.2 \%$ Triton X-100 in PBS). Antibodies were diluted to the appropriate concentration in blocking solution. Coverslips were incubated for $60 \mathrm{~min}$ in the antibody solution. The samples were subsequently washed three times in PBS and incubated for $30 \mathrm{~min}$ in PBS solution containing the fluorescence-conjugated secondary antibodies, and then washed five times with PBS and mounted in Mowiol. Fluorescence images were obtained with an inverted microscope (Olympus IX70), using a TILL monochromator as light source. Pictures were taken with an attached cooled CCD camera (Orca II-ER, Hamamatsu). ImageJ analysis software (National Institutes of Health) was used for synaptic density and dendritic length quantification. To reduce variability among different cultures and treatments, synaptic puncta were exclusively analyzed in proximal dendrites, starting from a clearly identified neuronal cell soma. Synaptic density represents the number of synapses per 100 micrometers of dendritic length. Hippocampal cultures were routinely treated with the peptide for $48 \mathrm{~h}$, unless otherwise indicated. Synaptic density shows some degree of variability among cultures (from 10 to 29 synapses per $100 \mu \mathrm{m}$ at day 10 in vitro). To normalize data from different cultures, the percentage of synaptic change was calculated as the average of different cultures under the same experimental conditions. As a control, we used sister untreated cultures grown in the same multiwell plate.

The following antibodies were used: an anti-bassoon monoclonal antibody (catalog \#VAM-PS003, Stressgen), a polyclonal sera against synapsin (catalog \#2312, Cell Signaling Technology), and a monoclonal antibody against gephyrin (catalog \#147011, Synaptic Systems), as well as the appropriate secondary antibodies (Invitrogen). To analyze spine density, cultures of GFP-actin-transfected neurons were fixed and processed in a similar manner. Spine pictures were taken with a Leica DMI 6000B microscope coupled to a Leica DFC 350 FX camera. ImageJ software was used to quantify spine densities.

\section{Sholl analysis}

Neuronal branching complexity was analyzed as follows: at days 4 and 6 in culture, low-density hippocampal cultures were stained with an antibody against MAP2B (Cell Signaling Technology). At days 10 and 21, we used the GFP-transfected neurons on high-density cultures. Using ImageJ software, low-magnification pictures from isolated neurons were digitally enhanced. Afterward, a series of concentric circles were drawn, centered on the cell body and gradually increasing in diameter in $20 \mu \mathrm{m}$ steps. A two-dimensional analysis was performed, counting the number of branches that intersected successive concentric circles (Sholl, 1953). Contour pictures were obtained from the same pictures following digital thresholding, using Image J software.

\section{Electrophysiology}

Spontaneous miniature EPSCs (mEPSCs) were recorded starting on day 12 in culture. The recording chamber was filled with a solution containing $137 \mathrm{~mm} \mathrm{NaCl}, 5 \mathrm{~mm} \mathrm{KCl}, 3 \mathrm{~mm} \mathrm{CaCl} 2,0.5 \mathrm{mM} \mathrm{MgCl}_{2}, 10 \mathrm{~mm}$ D-glucose, and $10 \mathrm{~mm}$ HEPES-NaOH, $\mathrm{pH}$ 7.3, adjusted to $310 \mathrm{mOsm} / \mathrm{kg}$. Tetrodotoxin (TTX) was used at a concentration of $1 \mu \mathrm{M}$. Whole-cell patch-clamp recordings were performed with electrodes filled with the following solution: $135 \mathrm{~mm} \mathrm{~K}$-gluconate, $18 \mathrm{~mm} \mathrm{KCl}, 9 \mathrm{~mm} \mathrm{NaCl}, 1 \mathrm{~mm}$ $\mathrm{MgCl}_{2}, 10 \mathrm{~mm}$ HEPES-KOH, pH 7.2, and 0.3 mM EGTA adjusted to 300 mOsm. An ATP regeneration mix (2 mM ATP, $10 \mathrm{~mm}$ phosphocreatine, $0.5 \mathrm{~mm}$ GTP, $2 \mathrm{~mm} \mathrm{MgCl}_{2}, 0.5 \mathrm{~mm}$ GTP, and $25 \mathrm{U} / \mathrm{ml}$ creatine phosphokinase) was routinely added to the internal solution. mEPSCs were recorded at a sampling frequency of $10 \mathrm{kHz}$. Frequency analysis was performed using Clampfit Event Detector software (Molecular Devices).

\section{Western blot quantification}

Cell culture. Hippocampal neurons were seeded at $50 \times 10^{4} / \mathrm{cm}^{2}$ on coated wells from a 24-well plate. Before lysis, the wells were washed two times with $\mathrm{PBS}\left(4^{\circ} \mathrm{C}\right)$ and then scrapped in $60 \mu$ lof lysis buffer $(62.5 \mathrm{~mm}$ Tris $\mathrm{HCl}, \mathrm{pH} 6.8,2 \%$ SDS, $10 \%$ glycerol, $100 \mathrm{~mm}$ DTT and $0.01 \%$ bromophenol blue). Cell lysates were collected and boiled at $85^{\circ} \mathrm{C}$ for $3 \mathrm{~min}$, sonicated during $5 \mathrm{~min}$, and finally clarified by centrifugation at $17,000 \times g$. The supernatants were stored frozen at $-80^{\circ} \mathrm{C}$. Samples were subjected to SDS-PAGE and Western blotting. Signals were detected with a chemoluminescent detection system (Immun-Star HRP, Bio-Rad). Signal detection and density quantification were performed using a LAS 3000 Image system (Fuji). The following antibodies were used: anti-actin monoclonal antibody (catalog \#A2547, Sigma), and polyclonal antibodies against Phospho-Akt (Ser473) and Akt (catalog \#9271 and \#4691, respectively, Cell Signaling Technology). LY294002, Akt 1/2 kinase inhibitor, and deguelin were purchased from Sigma. Unless otherwise indicated, in all biochemical experiments the peptide was added on day 10 in vitro, and cell lysis was performed $48 \mathrm{~h}$ later, on day 12. Control cultures were performed simultaneously. Phospho-Akt values were related to the total Akt amount, while synapsin and PSD95 were related to Actin levels. Average changes in phosphorylation and protein percentage values were normalized with respect to the control value, always included 
in the same Western blot membrane. Values $>100$ indicate an increase in protein levels; values $<100$ indicate a reduction.

Brain tissue. Briefly, hippocampi were isolated from rat brain and homogenized in lysis buffer containing commercial cell lysis buffer (catalog \#9803, Cell Signaling Technology) with the following supplements: leupeptin $1 \mu \mathrm{g} / \mathrm{ml}$, aprotinin $1 \mu \mathrm{g} / \mathrm{ml}$, orthovanadate $1 \mu \mathrm{g} / \mathrm{ml}$, and PMSF $1 \mu \mathrm{M}$. The homogenate was centrifuged at $8000 \mathrm{rpm}$ for $10 \mathrm{~min}$, and the supernatant was collected. Protein concentration was determined using the Protein-Assay reagent (Bio-Rad). For Western blots, $40 \mu \mathrm{g}$ of sample were loaded. Signals were detected using the corresponding infraredfluorescence-labeled antibodies (Li-Cor Bioscience) and viewed with an Odyssey Infrared Imaging System (Li-Cor Bioscience).

\section{Stereotaxis and immunohistochemistry}

Male adult Sprague Dawley rats (275-300 g) were purchased from Harlan. Before the experimental procedure, the animals were kept in the animal housing unit for 1 week. Animals were anesthetized with a mixture of xylazine $(10 \mathrm{mg} / \mathrm{kg})$ and ketamine $(70 \mathrm{mg} / \mathrm{kg})$ and were placed in a stereotaxic frame. Injections using a Hamilton syringe were administered into the CAl region of the dorsal hippocampus (bregma coordinates: $-2.8 \mathrm{~mm}$ anteroposterior, $-1.5 \mathrm{~mm}$ lateral, and $-2.8 \mathrm{~mm}$ dorsoventral) (Paxinos and Watson, 1998). All rats received a total volume of $1 \mu \mathrm{l}$ per injection. A construct of PTD4-rhodamine $(100 \mu \mathrm{M})$ diluted in CSF was injected in the case of control animals, while PTD4PI3KAc $(10 \mu \mathrm{g} / \mu \mathrm{l})$ diluted in water and 6\% DMSO was injected in the experimental group. Seventy-two hours after the stereotaxic injections, the animals were perfused transcardially with saline and $4 \%$ phosphatebuffered paraformaldehyde. Brain sections $(100 \mu \mathrm{m})$ including the dorsal hippocampus were obtained using a vibratome (VT-1000S, Leica) and stained with DAPI (Sigma). With the aid of a micromanipulator, individual neurons were injected by microiontophoresis with Lucifer yellow (8\% in 0.1 м Tris buffer, pH 7.4) (Elston and Rosa, 1997; Benavides-Piccione et al., 2002; Ballesteros-Yáñez et al., 2006). The microcapillary containing the neuronal tracer was backfilled with $\mathrm{LiCl}(0.1$ M). Neurons were filled under fluorescence microscopy by applying a continuous current $(20 \mathrm{nA})$ for $\sim 5 \mathrm{~min}$. The tissue was processed for immunohistochemistry with an antibody against Lucifer yellow (Sigma) and identified by a goat anti-rabbit secondary antibody conjugated to Alexa488 (Invitrogen). Only basal dendrites were selected for the analysis of spine density. Images stacked to different $z$-levels were taken under confocal microscopy, and a maximum intensity $z$-projection image was composed using ImageJ software. We have only quantified lateral spines, ignoring spines located on the top or bottom surface of the dendrites; thus, only spines arising from the lateral surfaces of the dendrites were included in the study. We can therefore assume that the results obtained were presumably an underestimate of the total number of spines. Because spine density has been shown to increase as a function of the distance from the soma, reaching a plateau $45 \mu \mathrm{m}$ away from it (RuizMarcos and Valverde, 1969; Elston and DeFelipe, 2002), to compare different cells we selected dendritic segments of the same length starting $45 \mu \mathrm{m}$ away from the cell body.

\section{Behavioral experiments}

A total of 44 male adult Sprague Dawley rats (Harlan), weighing 250-275 $\mathrm{g}$ at the beginning of the experiment, were individually housed in cages upon arrival and allowed to habituate to the animal housing conditions for at least 1 week before starting the experimental procedures. Light (12 $\mathrm{h}$ light/dark cycle) and temperature $\left(20^{\circ} \mathrm{C}\right)$ conditions were controlled, and food and water were provided without restriction. Rats were handled daily for $2 \mathrm{~min} / \mathrm{d}$ during the $3 \mathrm{~d}$ preceding the behavioral tests. After the habituation period, the rats were implanted with stainless steel guide cannulas aimed at the right lateral ventricle. They were anesthetized with xylazine $(10 \mathrm{mg} / \mathrm{kg})$ and ketamine $(70-100 \mathrm{mg} / \mathrm{kg})$, and mounted in a stereotaxic apparatus. A small hole was drilled through the skull, above the right lateral ventricle ( $1 \mathrm{~mm}$ posterior, $1.5 \mathrm{~mm}$ lateral, and $4.3 \mathrm{~mm}$ deep, relative to Bregma) (Paxinos and Watson, 1998), for implanting a stainless steel 22G cannula with a Teflon guide and fitted with a removable dummy cannula (Plastic One). The cannula was fixed to the skull with dental acrylic (Duralay 2244, Reliance). After the surgery, the ani- mals were allowed to recover for at least $5 \mathrm{~d}$ before performing the behavioral tests. Animal care procedures were conducted in accordance with the guidelines set by European Community Council Directive 86/ 609/EEC and the Cantonal Veterinary Authorities (Vaud, Switzerland).

\section{Elevated plus maze}

Animals were subjected to an Elevated Plus Maze protocol (EPM) to assign them to groups of equivalent anxiety levels. The EPM consisted of two opposing open arms $(45 \times 10 \mathrm{~cm})$ and two closed arms $(45 \times 10 \times$ $50 \mathrm{~cm})$ extending from a central platform $(10 \times 10 \mathrm{~cm})$ elevated $65 \mathrm{~cm}$ above the floor. The rats were individually placed on the central platform, facing a closed arm, and were allowed to explore the maze freely for 5 min. The behavior of each rat was monitored using a video camera, and the movements of the rats were automatically recorded and analyzed using a computerized tracking system (Ethovision 3.0, Noldus Information Technology). Entry into an arm was defined as the entry of all four paws into the arm.

\section{Fear conditioning}

Two experiments were performed to evaluate whether in vivo intracerebral ventricular injection with the PTD4-PI3KAc would affect the establishment of fear-conditioning memories. The first experiment was designed to evaluate the hippocampus-dependent, contextual, fearrelated memory [contextual fear conditioning (CFC)], and the second to assess the hippocampus-independent, auditory, fear-related memory [auditory fear conditioning (AFC)]. In both experiments, the animals were injected with $10 \mu \mathrm{l}$ of a CSF solution containing either $10 \mu \mathrm{g}$ of PTD4-PI3KAc or $10 \mu \mathrm{g}$ of PTD4 control peptide. Twenty-four hours after injection, the animals were submitted to a training session. Both training and testing took place in two identical rodent observation cages $(30 \times 37 \times 25 \mathrm{~cm})$, placed inside a sound-attenuating chamber. The floor of each cage consisted of 20 steel rods wired to a shock source and solid-state scrambler for the delivery of footshock stimuli (Panlab). Just before the experiment, the animals to be subjected to training or testing were transported from the colony room to the adjacent fearconditioning room. The conditioning chamber was thoroughly cleaned between animals with $1 \%$ acetic acid. During the training, the animal was allowed to freely explore the chamber for $160 \mathrm{~s}$. This was followed by three presentations of tone-shock pairings in which the tone $(20 \mathrm{~s} ; 800$ $\mathrm{Hz}, 80 \mathrm{~dB})$ coterminated with a foot shock $(0.5 \mathrm{~mA}, 1 \mathrm{~s})$. The intertone interval was $40 \mathrm{~s}$. Thirty seconds after the last shock, the animals were removed and placed in their home cages in the colony room. Testing was performed $1 \mathrm{~d}$ later. In the CFC experiment, the animals were exposed for 6 min to the training context, and on the following day to a context discrimination test (i.e., a novel chamber with a different contextual background). In the AFC experiment, $160 \mathrm{~s}$ after introducing the animals into a new context, they were presented with the same tone used for conditioning $(800 \mathrm{~Hz}, 80 \mathrm{~dB})$ for a period of $5 \mathrm{~min}$. In all cases, the animal's behavior was video recorded and later scored with the help of a video tracking system (Ethovision 3.0, Noldus Information Technology) by a researcher blind to the treatment. Freezing was scored as an index of fear, and defined as behavioral immobility (except for respiration movements) for at least $2 \mathrm{~s}$. For statistical analyses, freezing times were transformed into freezing percentage values.

\section{Statistics}

All data are represented as means \pm SEM and were analyzed using Prism software (version 4.0, Graphpad). The data were analyzed using the Student's $t$ test when appropriate. Significant levels were noted as follows: ${ }^{\star} p<0.05,{ }^{* *} p<0.01$, and ${ }^{* *} p<0.001$.

\section{Results \\ The cell membrane transduction peptide stimulates PI3K activity}

The effects of PI3K activation on synaptogenesis were analyzed using the peptide PTD4-PI3KAc. This peptide mimics phosphorylated tyrosine kinase receptor residues by binding to the $\mathrm{p} 85$ regulatory subunit of PI3K with great specificity. First, we verified the peptide ability to activate PI3K by measuring the phosphor- 
ylation levels of Akt, a downstream effector of PI3K. Serum-starved SH-SY5Y human neuroblastoma cells were treated with a peptide concentration of $50 \mu \mathrm{g} / \mathrm{ml}$, and the levels of phospho-Akt (Ser473) were quantified at $30,60,90,180$, and 360 min by Western blot (supplemental Fig. S1, available at www.jneurosci.org as supplemental material). PTD4-PI3KAc induced a modest, but sustained, increase in phospho-Akt levels from $152.7 \%$ after 30 min to $219.9 \%$ after $360 \mathrm{~min}$ (supplemental Fig. S1, available at www.jneurosci.org as supplemental material). As a negative control, cells were treated with the PTD4 peptide $(50 \mu \mathrm{g} / \mathrm{ml})$ without the p 85 interaction domain; its application did not modify phospho-Akt levels (supplemental Fig. S1, available at www.jneurosci.org as supplemental material). These data indicate that the peptide was able to stimulate PI3K activity, an effect that remained constant throughout the entire experimental period.

\section{PI3K stimulation increases the density} of synapses

Rat hippocampal neurons in culture were used as a model. Two different presynaptic protein markers were used to identify mature synapses: bassoon, a component of the presynaptic cytoskeleton at the active zone, and synapsin, a ubiquitous vesicular presynaptic protein (Ziv and Garner, 2004) (Fig. 1A). The overlapping of these two signals was the criterion used to identify synapses and to analyze the changes in synaptic density in response to PI3K activation (Friedman et al., 2000; Shapira et al., 2003).

First, we characterized the synaptic effect of PTD4-PI3KAc by quantifying the increase in the number of synapses in 10 day cultured neurons in response to three concentrations of the peptide $(0.5,5$, and $50 \mu \mathrm{g} / \mathrm{ml}$ ) during a $48 \mathrm{~h}$ treatment. Since PTD4-PI3KAc mimics the intracellular C terminus of the PDGF receptor, we used PDGF $(10 \mathrm{ng} / \mathrm{ml})$ as a positive control. To discard any possible effects due to the transduction process itself, the cultures were treated with $5 \mu \mathrm{g} / \mathrm{ml}$ a peptide containing only the transduction domain (PTD4). The quantification of the density of synapses indicates that the effects started at $0.5 \mu \mathrm{g} / \mathrm{ml}$ ( $24 \%$ increment) and reached its maximum at a concentration between 5 and $50 \mu \mathrm{g} / \mathrm{ml}$ (67\% and $49 \%$ increments, respectively) (Fig. $1 B$ ). In contrast, PDGF application alone did not show any synaptogenic effect (Fig. 1B) nor did the transduction fragment PTD4 (Fig. 1C).

Second, due to the peptidic nature of this activator, we investigated the temporal window of the synaptic increase,
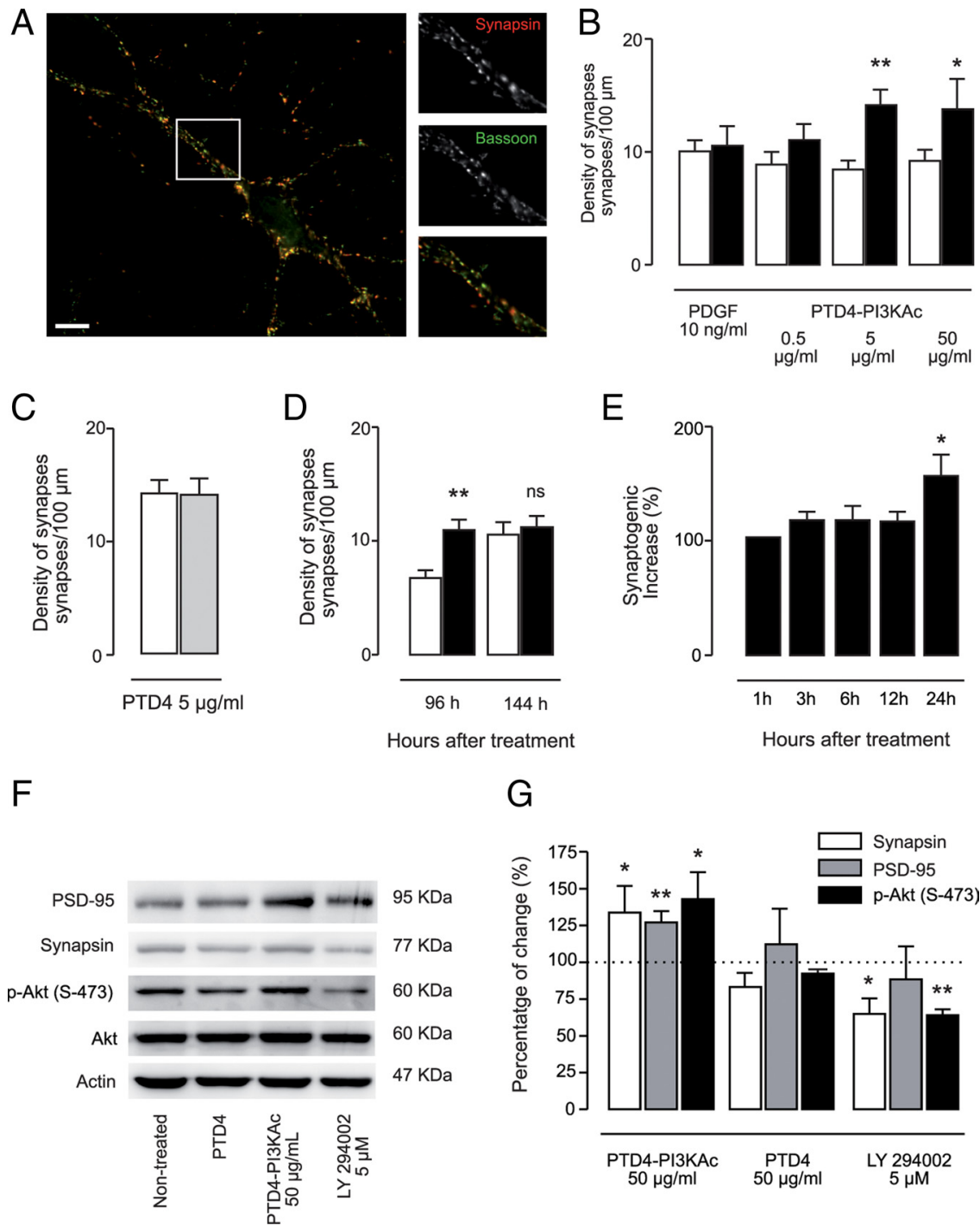

Figure 1. Concentration and time dependence of PI3K synaptogenic effects. $\boldsymbol{A}$, Hippocampal neurons in culture double stained with anti-bassoon and anti-synapsin antibodies. Mature synapses were quantified only if positive puncta to both bassoon and synapsin overlapped, and only from dendrites starting from a clearly identified neuronal cell body (scale bar, $5 \mu \mathrm{m}$ ). $\boldsymbol{B}$, Single dose-response curve after applying PTD4-PI3KAc at different concentrations on day 10 in vitro and quantifying synaptic density on day 12. Control experiments were performed in the presence of PDGF $(10 \mathrm{ng} / \mathrm{ml})$. The maximum effect of PTD4-PI3KAC was obtained using a concentration of $5 \mu \mathrm{g} / \mathrm{ml}$. A higher concentration of $50 \mu \mathrm{g} / \mathrm{ml}$ resulted in no further increase (Student's $t$ test). White bars: untreated cultures. Black bars: Treated cultures. ( $n=80$ neurons, two cultures). C, Transduction control. Synaptic density changes after applying $5 \mu \mathrm{g} / \mathrm{ml}$ transduction peptide alone (PTD4) under the same conditions. No changes in synaptic density were observed after $48 \mathrm{~h}$ of treatment. White bars: untreated cultures. Gray bars: PTD4 ( $n=30$ neurons, two cultures). $\boldsymbol{D}$, Peptide half-life in vitro. Time course of the effect of PTD4-PI3KAc after a single application of $5 \mu \mathrm{g} / \mathrm{ml}$ of the peptide on day 2 in vitro. The peptide remained active for at least $4 \mathrm{~d}$ in culture. Synaptic density was analyzed after 96 and $144 \mathrm{~h}$. A Student's $t$ test indicated significant differences after $96 \mathrm{~h}$, with no differences after $144 \mathrm{~h}$. White bars: untreated cultures. Black bars: treated cultures. ( $n=60$ neurons, three cultures). $\boldsymbol{E}$, Minimum time required for peptide effects. PTD4-PI3KAc effects on the density of synapses were manifest after a minimum of $24 \mathrm{~h}$. Nine-day-old cultures were treated with $5 \mu \mathrm{g} / \mathrm{ml} \mathrm{PTD4-PI3KAc}$, the cells were fixed, and the density of synapses was quantified at the indicated intervals. The graph represents the percentage of increase with respect to the untreated cultures. A statistically significant difference was only detected $24 \mathrm{~h}$ after the addition of PTD4-PI3KAC (Student's $t$ test; $n=50$, two cultures). $\boldsymbol{F}$, Representative immunoblot showing the changes in PSD95, synapsin and phospho-Akt (Ser-473) from a high-density hippocampal neuron culture treated with PTD4-PI3KAc (50 $\mu \mathrm{g} / \mathrm{ml})$, PTD4 (50 $\mu \mathrm{g} / \mathrm{ml})$, or LY294002 $(5 \mu \mathrm{M})$. Treatment was applied on day 10, and cellular lysis was conducted on day 12 in vitro. G, Summary graph of PI3K activity. PTD4-PI3KAc-treated cultures exhibited increased levels of phospho-Akt, synapsin and PSD95, compared with untreated cultures ( $n=33$, eight cultures). The transduction peptide PTD4 alone failed to modify either Akt phosphorylation or protein expression levels ( $n=4$, three cultures). Conversely, LY294002 significantly reduced phospho-Akt and synapsin levels ( $n=7$, two cultures). adding a single dose at day 2 in culture $(5 \mu \mathrm{g} / \mathrm{ml})$ and quantifying the effects after 96 and $144 \mathrm{~h}$. The data show that the synaptogenic effects remain for $96 \mathrm{~h}$ (Fig. $1 D$ ). At $144 \mathrm{~h}$ (day 8 in vitro), the synaptic density was similar to that of the un- 
treated cultures, indicating that the peptide was no longer active (Fig. $1 D$ ).

Third, we determined the minimum period of time required to increase the density of synapses. Nine-day-old neuronal cultures were treated with a single dose of PTD4-PI3KAc $(5 \mu \mathrm{g} / \mathrm{ml})$, and the density of synapses was quantified after $1,3,6,12$, and $24 \mathrm{~h}$ (Fig. 1E). The synaptogenic effect, normalized to untreated cultures, indicates a significant difference only after $24 \mathrm{~h}(57.1 \pm$ $18.7 \%$ increment). This value represents the time it takes for a synapse to be built after PI3K overactivation, and it is in agreement with the value obtained in Drosophila following PI3K gene activation (Martín-Peña et al., 2006).

Finally, we measured the ability of the peptide to modulate Akt phosphorylation in hippocampal cultures. The basal phosphorylation levels of Akt in neuronal cultures, and consequently its activity levels, were highly variable. To obtain a more robust and constant effect, the peptide concentration was raised to 50 $\mu \mathrm{g} / \mathrm{ml}$ (Fig. $1 \mathrm{~F}$ ). After $48 \mathrm{~h}$ of treatment, Akt phosphorylation at residue Ser- 473 increased to $142 \pm 18.2 \%$ over the control levels. Noticeably, this increase is compatible with the effect on synaptic density; furthermore, it demonstrates that the peptide remained active during this window of time. As expected, the addition of the PI3K inhibitor LY294002 (5 $\mu \mathrm{M})$ reduced Akt phosphorylation levels down to $64.1 \pm 3.8 \%$ (Fig. $1 G$ ). The control treatment using $50 \mu \mathrm{g} / \mathrm{ml}$ PTD4 did not significantly modify the basal Akt phosphorylation levels $(97.4 \pm 2.5 \%)$.

To further confirm the synaptogenic effects and to establish a reliable protein marker of synaptogenesis, we quantified the changes in the expression levels of synapsin, a ubiquitous component of all presynaptic terminals (Sudhof, 2004). In parallel to the phospho-Akt augmentation, PTD4-PI3KAc increased synapsin levels up to $129.8 \pm 18.5 \%$. On the other hand, in addition to decreasing phospho-Akt levels, treatment with LY294002 reduced synapsin levels to $64.9 \pm 10.5 \%$, compared with the untreated control cells. Cultures treated with PTD4 failed to show any change in synapsin expression $(83.1 \pm 9.6 \%)$ (Fig. $1 F, G)$.

Additionally, we quantified the levels of PSD95, a major postsynaptic component specific to glutamatergic synapses. While PTD4-PI3KAc increased PSD95 up to $127.1 \pm 7.6 \%$, neither PTD4 nor the PI3K inhibitor affected its levels (Fig. $1 F, G$ ). Thus, it can be concluded that the expression levels of two synaptic proteins and the phosphorylation of a PI3K target substratum are consistently modified by the upregulation or downregulation of PI3K activity.

In summary, the experiments described in this section helped us establish a working concentration and a time window for the synaptogenic effects of PTD4-PI3KAc, from a minimum time of $24 \mathrm{~h}$ to a maximum of $96 \mathrm{~h}$.

\section{The synaptogenic effects of PI3K activation are independent of culture age and synapse type}

In culture, hippocampal neurons develop extensive axonal and dendritic arbors, and form numerous synapses in a short period of time. Presynaptic specializations do not appear until day 3 , even though numerous cell contacts can be observed during the first $24 \mathrm{~h}$ (Fletcher et al., 1994; Friedman et al., 2000). Whereas axons can develop presynaptic specializations soon after they emerge from the cell soma, dendrites do not have the capability to induce synapses until they reach a critical maturation stage, usually after 5 d in culture (Fletcher et al., 1994; Ziv and Garner, 2001). Later, during the second and third weeks, hippocampal neurons grow into a dense network of dendrites, with spines appearing after 16-18 d in culture (Kaech and Banker, 2006). To cover all the developmental stages, we examined whether PI3K induces synaptic changes under two conditions: during a 2 week chronic treatment period, and after an acute single treatment of $48 \mathrm{~h}$ in 2- and 3-week-old cultures.

During the chronic experiment, the peptide PTD4-PI3KAc was added $(5 \mu \mathrm{g} / \mathrm{ml})$ every other day, starting on day 2 and continuing until day 12. Cultures were fixed and processed for immunostaining $48 \mathrm{~h}$ post-addition (from days 6 to 14) (Fig. 2A). The results show that the cumulative administration of PTD4PI3KAc is able to increase the density of synapses at all ages studied, although the effects are more prominent during the first few days in culture (Fig. 2A). The synaptogenic effect exhibits a maximum during the first week in culture: $69.5 \pm 8.4 \%$ and $51.2 \pm 13.3 \%$ of synaptic density increase after 6 and $8 \mathrm{~d}$ in vitro, respectively. This is followed by a progressive reduction to a $32.8 \pm 11.3 \%, 24.0 \pm 9.0 \%$, and $25.7 \pm 0.8 \%$ increase at days 10,12 , and 14 , respectively $(n=$ 440 neurons, four cultures) (Fig. $2 G$ ).

The density of synapses was also quantified $48 \mathrm{~h}$ after a single application on day 10 (Fig. $2 \mathrm{~B}$ ). In these cultures, the density of synapses increased to $42.8 \pm 8.5 \%$ ( $n=80$, four cultures) (Fig. $2 G$ ). To test the effect in older cultures (3 weeks), a single treatment was administered on day 19 , and quantification was performed at day 21. In this experiment, synaptic density increased by $38.8 \pm 8.1 \%$ (Fig. $2 C, G$ ), a value similar to that obtained on day 12 ( $n=80$, three cultures).

To confirm the involvement of PI3K, an experiment in the opposite direction was performed by inhibiting PI3K activity with the selective inhibitor LY294002 $(5 \mu \mathrm{M})$. Its addition reduced synaptic density down by $40.9 \pm 6.3 \%$, 48 h later (Fig. $2 D-G)$, clearly implicating PI3K activity in synapse formation and maintenance ( $n=40$, two cultures).

The majority of the synaptic contacts present in hippocampal neurons in culture are known to be glutamatergic (Rao et al., 1998); under our culture conditions, the number of inhibitory neurons was close to 6\% (Benson et al., 1994). To study whether the overactivation effects were synapse type specific (excitatory or inhibitory), we quantified the changes in the number of inhibitory and excitatory synapses using double immunostaining against bassoon/PSD95 (Kornau et al., 1995) (Fig. 2E; supplemental Fig. S2, available at www.jneurosci.org as supplemental material) and synapsing/gephyrin (a component of postsynaptic GABAa and glycine synapses) (Kneussel and Betz, 2000) (Fig. $2 F)$. The experimental data indicate that PI3K overactivation can increase the density of both types of synapses $36.3 \pm 5.1 \%(n=$ 60 , two cultures) and $29.1 \pm 8.2 \%(n=60$, two cultures), respectively, for inhibitory and excitatory synapses (Fig. $2 G$ ).

The results of this experimental section, represented as the percentage of increments normalized to the control cultures, are summarized in Figure 2G. The progressive decrease in percentage during the chronic treatment clearly indicates that some sort of desensitization is taking place. The effectiveness of the PTD4PI3KAc treatment in the single-application experiments, comparing the effects on day 12 of the chronic and acute experiments, also suggests that the cumulative presence of the peptide could have a desensitizing effect.

Finally, from these experiments we conclude that the effect of PI3K on synapse density is independent of the developmental stage of the culture or the type of synapse.

\section{The new synapses are functional}

To address the functionality of these de novo synapses, we performed electrophysiological recordings on cultured hippocampal neurons, monitoring spontaneous miniature events. Under 

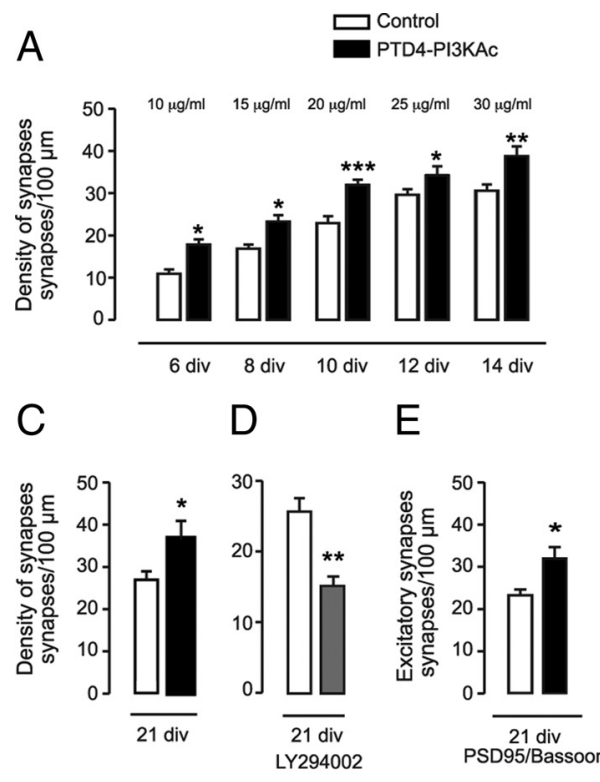

$\mathrm{E}$
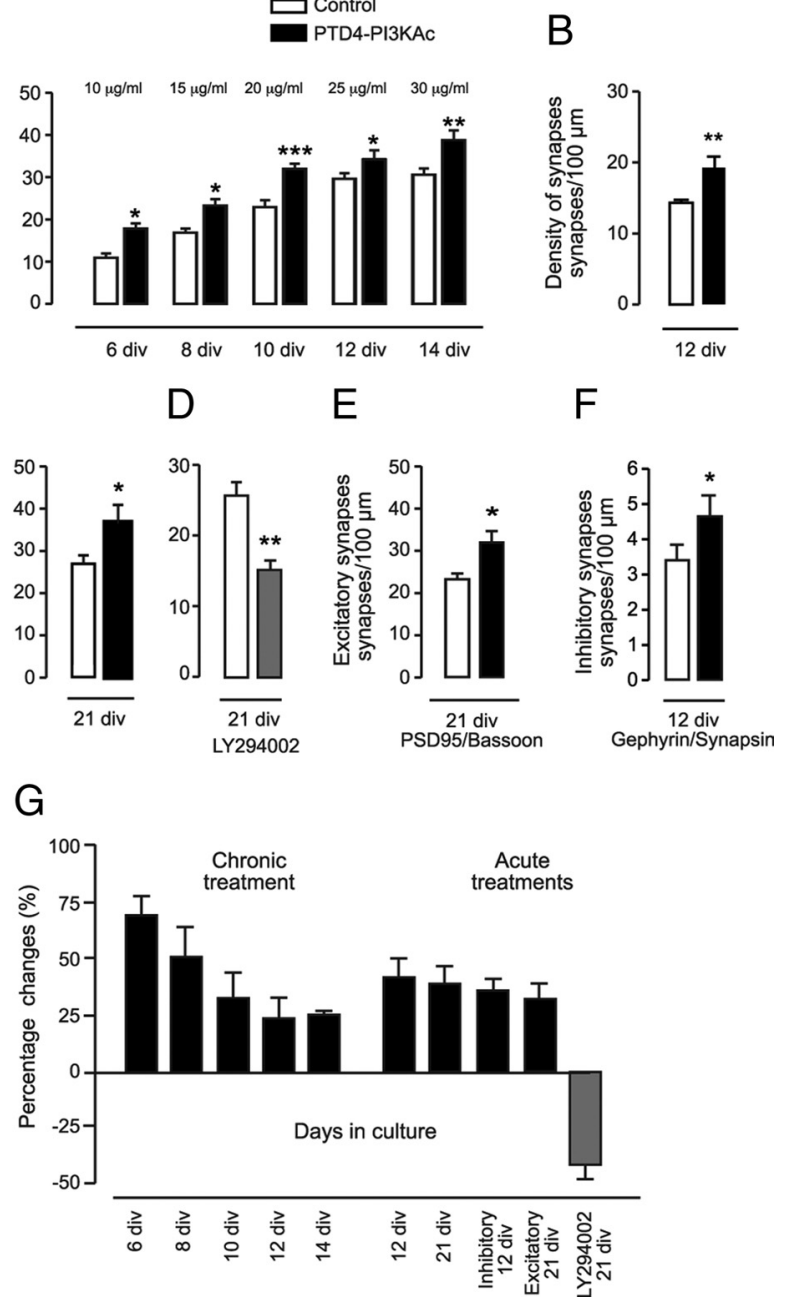

Figure 2. PTD4-PI3KAc increases synaptogenesis in rat hippocampal neurons in culture. $\boldsymbol{A}$, Temporal evolution of synaptic density in a hippocampal neuronal culture. In untreated (control) cultures, synaptic density progressively increased. PTD4-PI3KAC ( $5 \mu \mathrm{g} / \mathrm{ml})$ was applied every other day, starting on day 2. The density of synapses was analyzed on the indicated days. The estimated maximum cumulative concentration of PTD4-PI3KAc is indicated at the top of the graph. The culture developed in the presence of the peptide showed significant differences on all days (Student's test; $n=200$ neurons). $\boldsymbol{B}$, An example of the effects of a single PTD4-PI3KAC application ( $5 \mu \mathrm{g} / \mathrm{ml})$ on the density of synapses in a hippocampal neuronal culture of $10 \mathrm{~d}$ in vitro ( $n=30$ neurons). The density of synapses varied among cultures (see the comparison of values at $12 \mathrm{~d}$ in vitro in $\boldsymbol{A}$ and $\boldsymbol{B}$; see also Materials and Methods). Note, however, that the treated cultures always showed density values higher than controls. $C$, Effects on the density of synapses in a 3-week-old culture. PTD4-PI3KAc was added on day 19, and synaptic density quantified on day $21(n=30)$. D, Effects on the density of synapses after PI3Kinhibition. On day 19 in culture were treated with LY294002 $(5 \mu \mathrm{M})$, resulted in a significant loss in synapse density $48 \mathrm{~h}$ later $(n=40)$. E, Effects over excitatory synapses. Synaptic density was evaluated on day 21. Excitatory synapses were identified by double staining with bassoon and PSD95 antibodies $(n=30)$. $\boldsymbol{F}$, Effects over inhibitory synapses. Synaptic density was evaluated on day 12 . Inhibitory synapses were identified by double immunostaining against gephyrin and synapsin $(n=$ 30). G, Summary plot of the synaptogenic effect. Left, Average data from six different cultures chronically treated with PI3K activator, as in $A$. Synaptic increase showing a biphasic curve, with a more pronounced effect during the first days in culture, followed by a decline (days 8 and 10), and reaching an asymptotic value on day $10-14$ in vitro. Right, Summary of all acute application experiments, as shown in $\boldsymbol{B}-\boldsymbol{F}$. Similar percentages of increase were obtained in all culture stages tested.

our recording conditions, at a holding membrane potential of $-70 \mathrm{mV}$ and in the presence of $2 \mathrm{~mm} \mathrm{MgCl}_{2}$, the majority of spontaneous miniature postsynaptic currents (mEPSCs) result from postsynaptic AMPA receptor activation (Bekkers and Ste-
A

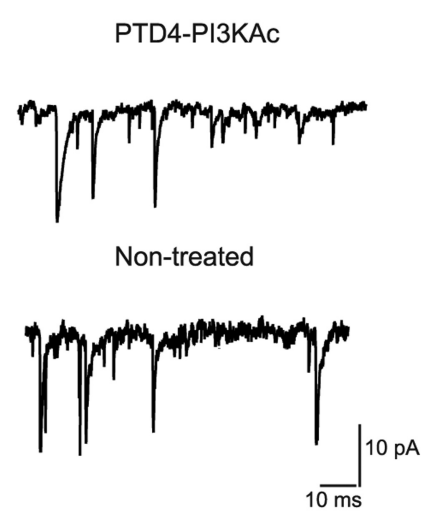

$\mathrm{B}$

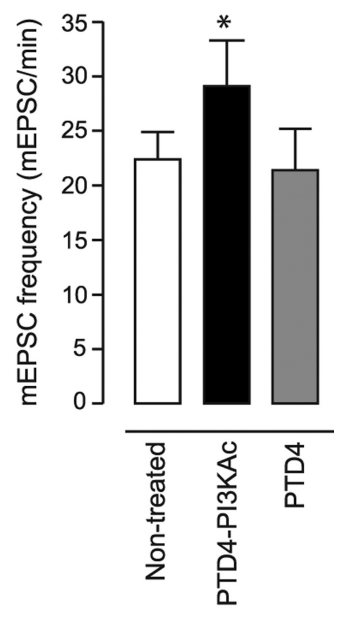

C

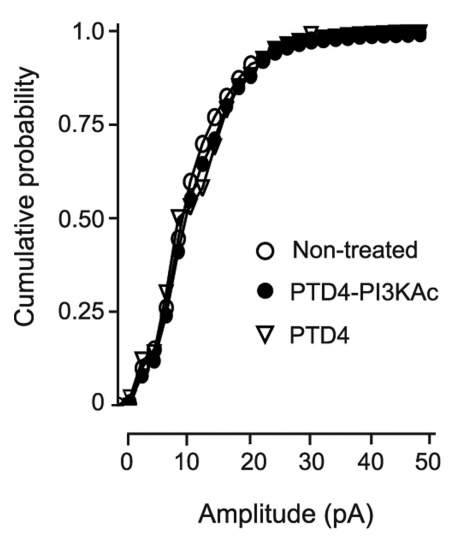

D

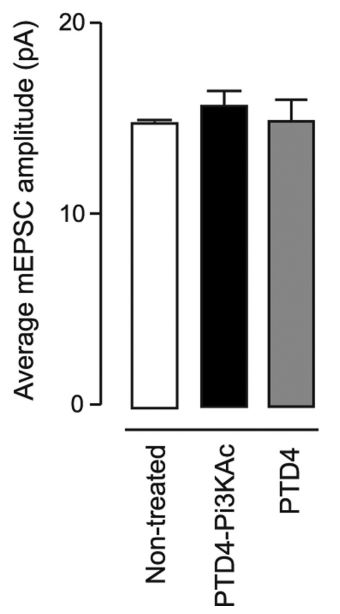

Figure 3. PI3K-induced synapses are functional. mEPSC frequency was recorded from hippocampal neurons in culture under three experimental conditions: treated with PTD4-PI3KAC (5 $\mu \mathrm{g} / \mathrm{ml})$; untreated; and treated with PTD4 $(5 \mu \mathrm{g} / \mathrm{ml})$. All treatments lasted $48 \mathrm{~h}$, from day 10 to 12. $A$, Representative neuronal current traces showing mEPSCS. TTX $1 \mu$ m was regularly applied to prevent evoked responses. $\boldsymbol{B}$, Mean mEPSC frequency average plot. PTD4-PI3KAc treatment resulted in an increase of $29 \%$ in mEPSC frequency. $C$, The cumulative frequency plot of all recorded mEPSC sizes failed to show significant differences among treatments. D, Mean mEPSC size plot. No differences were found among any of the treatments. A minimum of 10 neurons from three different cultures were recorded for each condition.

vens, 1989). Their frequency greatly depends on neuronal plating density and culture age. Thus, to minimize variability, all cultures were plated at the same cellular density, and electrophysiological recordings were performed on 12-day-old cultures treated during the previous $48 \mathrm{~h}$ with $5 \mu \mathrm{g} / \mathrm{ml}$ PTD4-PI3KAc (Fig. $3 A$ ).

We compared the mean frequency (mEPSCs/min) under the following three conditions: cultures treated with PTD4-PI3KAc $(5 \mu \mathrm{g} / \mathrm{ml})$; untreated cultures growing under the same conditions; and cultures treated with transduction peptide PTD4 (5 $\mu \mathrm{g} / \mathrm{ml}$ ) as a control for any possible changes attributable to the transduction process. Despite the large variability among neurons, the mean frequency average in the treated cells was significantly higher than that of untreated and control cells (Fig. 3B). The mEPSC frequency averages in untreated cells and those treated with PTD4 were $22.4 \pm 3.5$ and $21.4 \pm 3.8$ per minute, respectively, while in PTD4-PI3KAc-treated neurons it increased to $29.1 \pm 4.2$ per minute, representing a $29.9 \%$ increase (Fig. $3 B$ ). 
A $\quad 4$ div
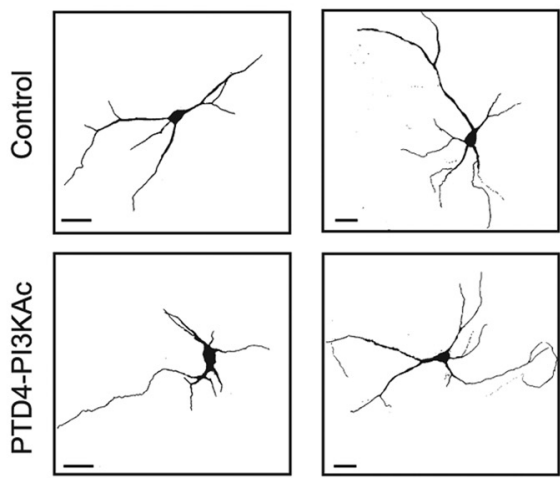

B

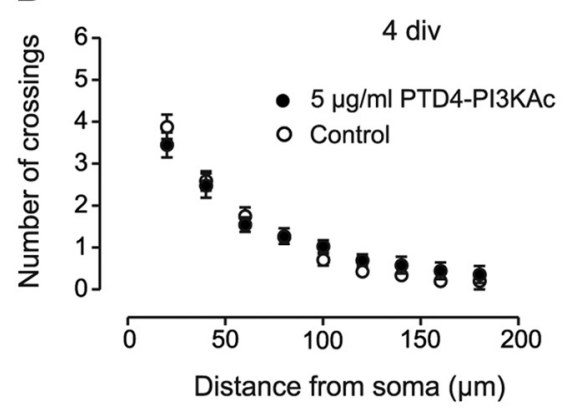

D

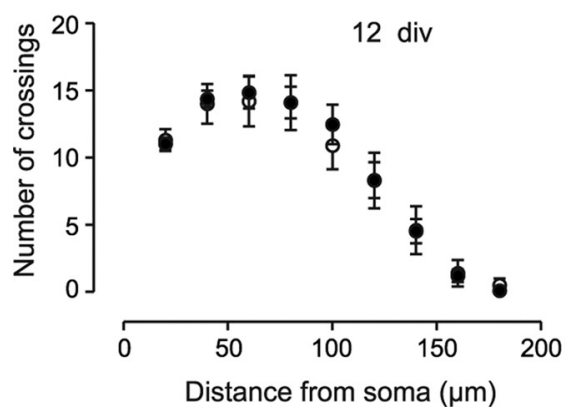

12 div
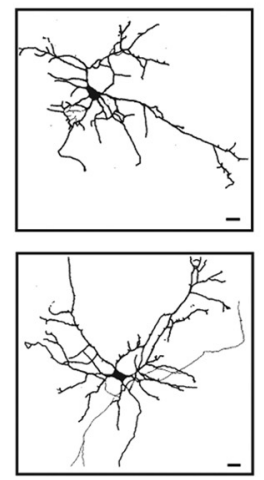

C

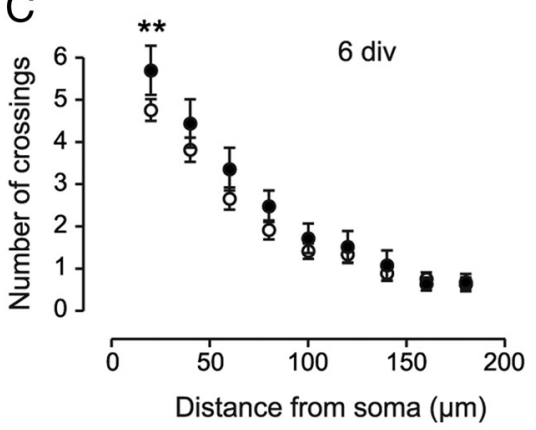

$E$

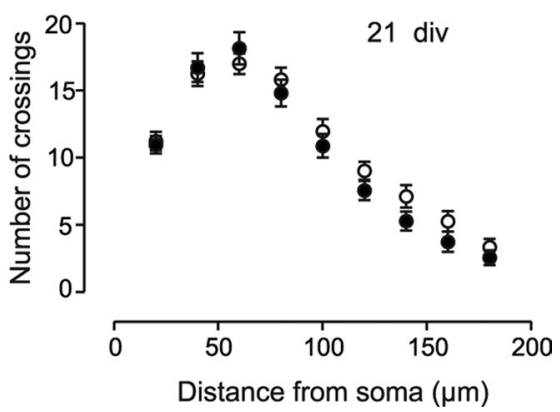

Figure 4. PI3K promotes neurite branching only in young neurons. $A$, Representative digital threshold micrographs of neurons stained with MAP2B ( 4 and $6 \mathrm{~d}$ in vitro) and transfected with CMV-GFP (12 and $21 \mathrm{~d}$ in vitro) in control (top) and PTD4-PI3KACtreated ( $48 \mathrm{~h}$ after the addition of $5 \mu \mathrm{g} / \mathrm{ml}$ ) cultures (bottom). Scale bar, $10 \mu \mathrm{m}$. $\boldsymbol{B}-\boldsymbol{E}$, Sholl analysis graph of neuritic-dendritic arborizations from untreated cultures (white circles) and treated (black circles). Analyses were performed at the indicated times. The horizontal axis represents the distance from the cell soma, whereas the vertical axis shows the number of crossings. The number of primary dendrites was statistically different from the controls only on day 6 in vitro (Student's $t$ test). div, Days in vitro.

To test for possible changes in mEPSC quantal size, we compared the mEPSC amplitude distribution under all three experimental conditions. The cumulative graph did not indicate a significant change in quantal size (Fig. 3C), suggesting that the treatment does not modify the AMPA receptor sensitivity. The average quantal sizes for untreated, PTD4-PI3KAc-treated, and PTD4treated cultures were $14.7 \pm 0.1 \mathrm{pA}, 15.5 \pm 0.8 \mathrm{pA}$, and $15.1 \pm 1.2$ pA, respectively (Fig. $3 D$ ). These data allow us to conclude that PI3K activation induces the formation of new functional synapses.

\section{Synaptogenesis and dendritogenesis are differentially modulated by PI3K}

Previous studies using hippocampal neurons in culture indicate that the constitutive activation of PI3K (overexpressing a membrane tagged p110) modifies dendrite morphology during the first 2 weeks in culture (Jaworski et al., 2005). This feature raises the question of whether modulation of the number of synapses is coordinately regulated with changes in dendritic complexity. To quantitatively analyze the role of PI3K activation over neuronal branching, we have used the Sholl analysis (Sholl, 1953) on cells after 1, 2, and 3 weeks in culture (Fig. 4A). A microtubule-associated protein monoclonal antibody (MAP2B) was used to stain the dendritic tree of neurons, either untreated or treated with PTD4-PI3KAc for $48 \mathrm{~h}$, after $4-6 \mathrm{~d}$ in culture. PI3K activation failed to modify dendrite morphology at day 4 (Fig. $4 B)(3.8 \pm 0.2$ vs $3.4 \pm$ 0.2 , respectively, crossings for control and PI3K-activated neurons, $n=56$ for each condition, four cultures), but it increased the number of primary dendrites at day 6 from $4.7 \pm 0.2$ to $5.7 \pm 0.5$ crossings (Fig. $4 C)$ ( $n=37$ for each condition, four cultures). This age coincides with the time at which the stronger effects on synaptic density were observed (Fig. 2G).

After $10 \mathrm{~d}$ in culture, neurons exhibit a large and complex dendritic tree, which is very difficult to trace as the arborizations from different neurons tend to overlap (Kaech and Banker, 2006). For this reason, we transfected cells with a GFP encoding plasmid that allowed us to visualize single-neuron arborizations. The PI3K activation effects on dendritic branching were studied on days 12 and 21, having applied the peptide $48 \mathrm{~h}$ earlier. The Sholl dendritic analysis indicated no differences in arborization complexity between untreated and PTD4-PI3KAc-treated neurons at $12(10.7 \pm 0.5$ vs $11.1 \pm 0.4$ crossings, $n=41$ for each condition, three cultures) or 21 (11.2 \pm 0.7 vs $10.9 \pm 0.6$ crossings, $n=34$ for each condition, three cultures) days in vitro (Fig. $4 D, E$ ). By contrast, the same treatment increased the density of synapses by close to $40 \%$ at both culture ages. Therefore, we can infer that synaptogenesis and dendritogenesis are differentially regulated by PI3K.

\section{Synaptic increase is independent of cell density}

Dendritic growth and synaptogenesis are independently regulated by PI3K activation; however, it is still possible that if axonal growth is underestimated by the Sholl analysis, it could contribute to the synaptogenic effect. In vitro, synaptic formation and maturation depend to a large extent on neuronal plating density and therefore of axonal complexity. Several factors such as the presence of growth factors and, mainly, the distance the axon must grow to find a target account for the actual synaptic density (van den Pol et al., 1998). We reasoned that if PI3K-induced synaptogenesis is dependent on new neuronal growth, either dendritic or axonal, then the increase in synapses should be proportional to the density of neurons. Thus, we measured the per- 


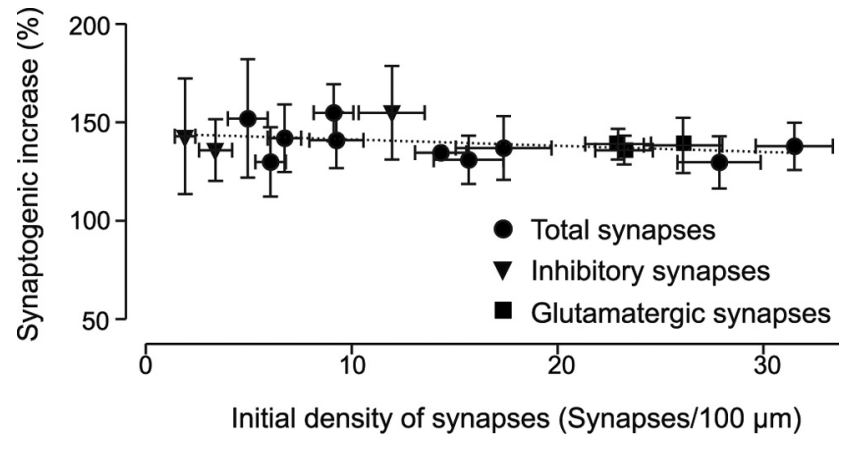

Figure 5. The synaptogenic effect does not depend on the density of synapses. Plot of the percentage of synaptic increase (vertical axes) versus the initial synaptic density, estimated from the control culture conditions. Only single-dose application experiments (effect after $48 \mathrm{~h}$ ) were plotted. Black circles represent total synapses (bassoon-synapsin), closed squares correspond to excitatory synapses (bassoon/PSD95), and inverted triangles indicate inhibitory synapses (gephyrin-synapsin). Linear regression of the experimental points yields a line with a slope not significantly different from zero $(n=23 ; y=-0.3 \pm$ $\left.0.2 \times+144.4 ; r^{2}=0.13\right)$.

centage of synaptic increase after PTD4-PI3KAc treatment and plotted it against the control synaptic density of each experiment from the $48 \mathrm{~h}$ treatments only (Fig. 5). A linear regression with either a positive or negative slope would indicate some degree of correlation between both parameters. However, the linear regression of the data yields, a slope that is not statistically different from zero $\left(y=-0.3 \pm 0.2 \times+144.4 ; r^{2}=0.13\right)$, indicating that there is no association between these two variables. This result, in combination with the Sholl analysis, further demonstrates that PI3K activation has a direct synaptogenic effect that is independent from neuritogenesis.

\section{$\mathrm{PI} 3 \mathrm{~K} / \mathrm{Akt} / \mathrm{mTOR}$ regulates the expression of synaptic proteins}

We aimed to identify the main components of the canonical PI3K-Akt signaling pathway. It is known that Akt is the major signaling target of PI3K activation. To further characterize the synaptogenic role played by Akt in our experiments, we used two Akt inhibitors with different modes of action: Akt 1/2 inhibitor and deguelin (Chun et al., 2003; Barnett et al., 2005). When hippocampal cultures were treated with either Akt $1 / 2$ inhibitor or deguelin for $48 \mathrm{~h}$, synapsin displayed a 50\% reduction (Fig. 6A) and phospho-Akt levels were also consistently reduced (Fig. $6 A$ ). The combined addition of Akt 1/2 inhibitor and PTD4-PI3KAc reduced synapsin levels by $41.2 \pm 16.3 \%$, indicating a prevalence of the inhibitor's effect, which demonstrates that Akt is downstream from PI3K in the pathway (Fig. 6C). However, when PSD95 levels were examined, Akt inhibition by deguelin or Akt $1 / 2$ did not affect its levels, nor did PI3K inhibition by LY294002 (Fig. 6A,C). This result suggests a relatively slow turnover of PSD95 with respect to presynaptic vesicular proteins (Ehlers, 2003; Velho and Mello, 2008).

One of the downstream Akt-regulated proteins, mTOR, is involved in the control of cell size, synaptic plasticity, and axonal regeneration, acting primarily through the phosphorylation of p70S6K (Cammalleri et al., 2003; Hay and Sonenberg, 2004; Jaworski and Sheng, 2006). This being the case, we proceeded to examine the possible role of $\mathrm{mTOR}$ in PI3K-dependent synaptogenesis by using its inhibitor (rapamycin). In neuronal cultures, rapamycin $(20 \mathrm{nM})$ reduces synapsin levels to $71.4 \pm 8.4 \%$ after $48 \mathrm{~h}$ of treatment (Fig. $6 D, E$ ). Interestingly, the combined action of the PI3K activator and rapamycin increased synapsin levels by
$25 \%$ (from the inhibited value to $97.1 \pm 13.9 \%$ ). This percentage was similar to that obtained when PTD4-PI3KAc was added by itself (29\%) (Fig. 1D). Since rapamycin did not block the effect of PTD4-PI3KAc, the result is compatible with a PI3K-mediated synaptogenic pathway independent of mTOR activation.

In parallel, the changes in synapse density after Akt/mTOR inhibition were quantified in a 12-day-old culture treated for $48 \mathrm{~h}$ with $20 \mathrm{~nm}$ rapamycin or $2.5 \mu \mathrm{M}$ Akt $1 / 2$ inhibitor. On average, synaptic density was reduced by $40 \%$ (37.8 and $40.8 \%$, respectively, after rapamycin and Akt $1 / 2$ inhibitor; $n=40$, two cultures) (Fig. 6F). Considered as a whole, the biochemical data indicate that the increase in the density of synapses is accompanied by an augmentation of synaptic protein expression, an effect that is mediated by Akt independently of mTOR.

\section{PI3K induces spinogenesis in adult neurons}

Dendritic spines are the receptive sites for most excitatory synapses in the mammalian nervous system. They are an excellent model for studies on synaptogenesis and short- and long-term synaptic plasticity (Yuste and Bonhoeffer, 2004). We studied the morphological plasticity of dendrites in vivo in adult male rats (Sprague Dawley) by measuring spine density after stereotaxic injections of PTD4-PI3KAc $(1 \mu \mathrm{l}, 10 \mu \mathrm{g} / \mu \mathrm{l})$ in the dorsal hippocampus [bregma coordinates: $-2.8 \mathrm{~mm}$ anteroposterior, $-1.5 \mathrm{~mm}$ lateral and $-2.8 \mathrm{~mm}$ dorsoventral (Paxinos and Watson, 1998)]. PTD4-rhodamine was used both as a control of spine density and to monitor peptide diffusion in control animals. After $72 \mathrm{~h}$, experimental and control animals were killed, and their brains were processed for Lucifer yellow tracer microinjection and counterstained with an antibody against Lucifer yellow to enhance the signal (Elston and Rosa, 1997; Benavides-Piccione et al., 2002; Ballesteros-Yáñez et al., 2006) (Fig. 7A; supplemental Fig. S3, available at www.jneurosci. org as supplemental material). As explained in Materials and Methods, all measures were performed on basal dendritic segments starting $45 \mu \mathrm{m}$ away from the soma, since that is the distance at which spine density reaches a relatively constant value. Spine density was quantified in hippocampal CA1 neurons of five control (2646 spines from 44 dendrites, 5 animals) and five treated rat brains (3050 spines, from 38 dendrites, 5 animals) (Fig. 7C). The results indicate that PTD4-PI3KAc injections increased spine density by $26 \%$ over the controls, raising the mean average density from $0.95 \pm 0.03$ under control conditions to $1.25 \pm 0.06$ after the treatment.

Results in the same direction were obtained when the density of spines was quantified in neurons in culture. In hippocampal cultures, the dendritic spines begin to appear on days 16-18 in vitro, and are abundant after 3 weeks of culture. To visualize and quantify the density of spines, cultured hippocampal neurons were transfected with a plasmid encoding GFP-actin (Fig. 7B). GFP-actin localizes to spine heads in transfected neurons (Fischer et al., 1998). In addition, we used synapsin as a presynaptic marker. The data indicate that $\sim 80-90 \%$ of the entire population of GFP-actin-positive spines also showed synapsin immunostaining, which leads us to conclude that the majority of the spines under our culture conditions were harboring mature synapses (supplemental Fig. S4, available at www.jneurosci.org as supplemental material). By counting dendritic spines enriched in GFP-actin (Fig. 7B), we quantified the density of spines on day 21 in culture, $48 \mathrm{~h}$ after adding the peptide (Fig. 7C). Remarkably, PI3K activity also increased the density of spines in cultured neurons, with an average increase from three cultures of $22 \%$ (Fig. $7 C)$. To study the time required for PI3K to induce the formation 
A

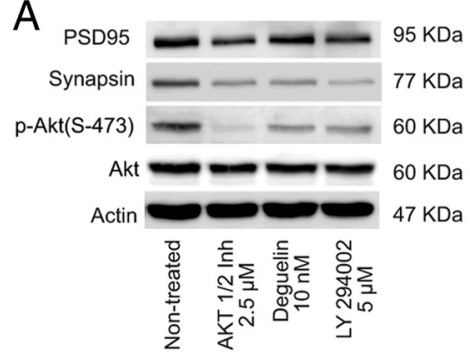

B

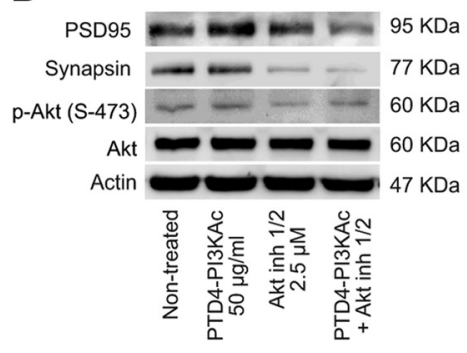

D

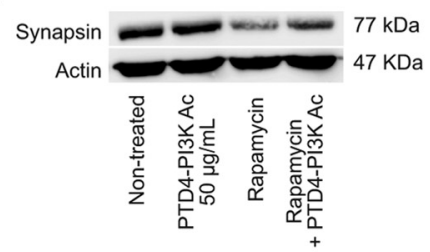

C

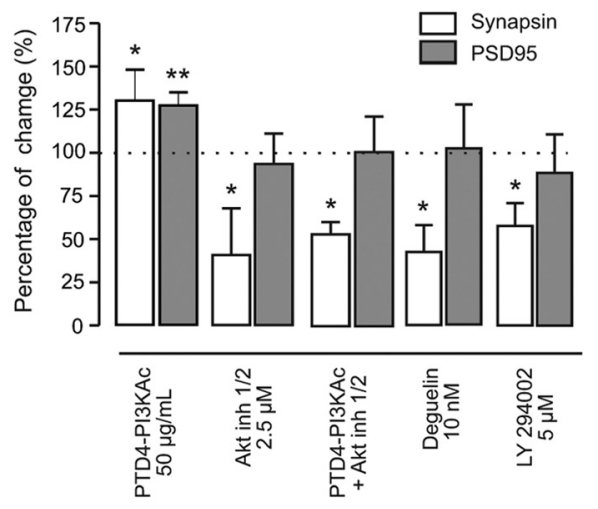

E

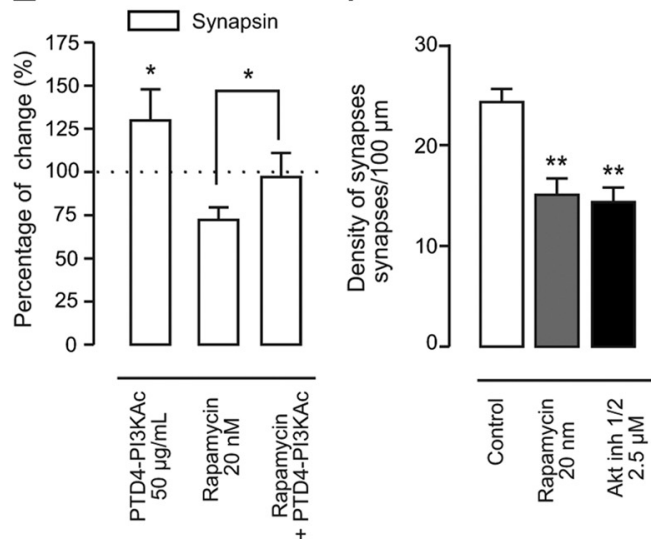

Figure 6. Molecular signaling downstream of PI3K activation. $\boldsymbol{A}$, Representative Western blot showing the Akt inhibition effects. PSD95, synapsin, and phospho-Akt expression levels were analyzed in response to Akt 1/2 inhibitor and deguelin. The PI3K inhibitor LY294002 was included as a negative control. $\boldsymbol{B}$, Representative Western blot of PSD95, synapsin and phospho-Akt levels in response to PTD4-PI3KAC alone or in combination with Akt 1/2 inhibitor. C, Summary graph of the effects of manipulating PI3K-Akt signaling on synapsin and PSD95 regulation. Akt inhibition reduced synapsin basal levels by $\sim 50 \%$ (Akt $1 / 2$ inhibitor, $n=6$; deguelin, $n=4$ ). The joint application of Akt 1/2 inhibitor and PTD4-PI3KAc reduced synapsin levels, blocking the synapsin PI3K-dependent upregulation $(n=4)$. However, while PSD95 levels increased in hippocampal cultures treated with PTD4-PI3KAC, no statistically significant differences were found among PSD95 levels when the PI3K-Akt pathway was inhibited $(n=15)$. Student's $t$ test. $\boldsymbol{D}$, Representative immunoblot of synapsin levels after rapamycin-mediated inhibition of mTOR. $\boldsymbol{E}$, Average plot of all experiments. Rapamycin reduced synapsin expression down to 71.4\%. PTD4-PI3KAc combined with rapamycin counteracted the effect of rapamycin alone, raising synapsin levels to $97.7 \%$ ( $n=7$, three cultures). $\boldsymbol{F}$, Synaptogenic effects of Akt/mTOR inhibition in 19-day-old cultures treated for $48 \mathrm{~h}$ with the indicated concentrations. Synaptic density (synapsin/bassoon) was reduced by 37.8 and $40.8 \%$, respectively, after treatment with rapamycin and Akt inhibitor.

of new spines, we performed a time course experiment at 12,24, and $48 \mathrm{~h}$. No significant differences were found $24 \mathrm{~h}$ after adding the peptide; only after $48 \mathrm{~h}$ of treatment were the differences between the control and treatment groups significantly different (Fig. 7D). As expected, the PTD4 treatment did not elicit changes in spine density (Fig. 7D). Considered together, the culture and in vivo data indicate that PI3K activity is able to control the density of spines in a fully mature system.

\section{PI3K activation leads to changes in behavior}

The correlation between spine density changes and learning and memory processes is well documented (Segal, 2005). Our reported increase in spine density in vivo prompted us to perform a behavioral assay as functional proof of the activity of the de novo synapses induced by PTD4-PI3KAc. To analyze any possible changes in associative learning due to PI3K activation, we performed a rodent contextual fear-conditioning test that evaluates memory processes depending on the dorsal hippocampus and the amygdala (Kim and Fanselow, 1992; Phillips and LeDoux, 1992; LopezFernandez et al., 2007). Animals were matched according to their anxiety levels (supplemental Figs. S5A, S6 A, available at www.jneurosci.org as supplemental material) and distributed into two equivalent groups, each receiving an intracerebral ventricular injection of either the PTD4 transduction domain (control; $n=10$ ) or the PTD4-PI3KAc peptide solution (10 $\mu \mathrm{g} ; n=10) 1 \mathrm{~d}$ before training. Interestingly, while the PTD4-PI3KAc-injected animals showed normal freezing responses to the shocks during conditioning $\left(t_{(18)}=2,25 ; p=0.036\right)$ (Fig. 8A), they displayed higher conditioned fear responses to the context (i.e., freezing) than control animals when tested for memory recall $24 \mathrm{~h}$ after conditioning (day 2, context test) (Fig. 8A; see supplemental movie SM1, available at www.jneurosci. org as supplemental material). To discard potential unspecific effects, freezing responses were also measured in a different environment (i.e., contextual change); however, no differences were observed between control and treated animals, indicating that the memory effects observed in the PTD4-PI3KAc-treated animals are context dependent (PTD4 $=15.2 \pm 2$ and PTD4-PI3KAc $=17.4 \pm 3$; n.s.) (see supplemental movie SM2, available at www. jneurosci.org as supplemental material). Furthermore, to assess whether the observed effects were specific to hippocampal function or whether the peptide could affect other learning or emotional processes, we designed a new experiment to test the effect of the peptide on acoustic fear conditioning, an amygdala-dependent (but not hippocampus-dependent) task. To this end, two series of 11 animals, matched as well for their anxiety levels (supplemental Figs. S5B and S6B, available at www.jneurosci.org as supplemental material), were injected with either PTD4-PI3KAc or PTD4 $(10 \mu \mathrm{g}) 1 \mathrm{~d}$ before training them for auditory fear conditioning. The results indicate that PTD4-PI3KAc did not affect the memory required for this task, with control and treated animals showing equivalent freezing values both before and during tone exposure at testing (n.s.) (Fig. 8B).

In parallel, to determine the efficiency of the peptide in modulating PI3K activity in vivo, we injected a new group of animals with either PTD4-PI3KAc or PTD4 control peptide at the level of the right lateral ventricle ( $n=3$ for each condition). Forty-eight hours after injection, the animals were killed and phospho-Akt levels were measured in the right hippocampus of each animal. The mean value of the three animals indicates a $27.4 \pm 7.8 \%$ increase in phospho-Akt levels in PTD4-PI3KAc-injected animals (Fig. 8C,D). Similar results (a $35.1 \pm 15.1 \%$ increment) were obtained when an ELISA phospho-Akt protocol was used (data not shown). Together, these results strongly suggest that 
A
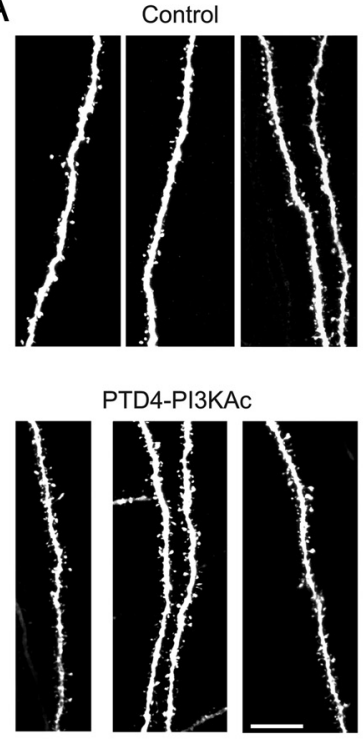

B
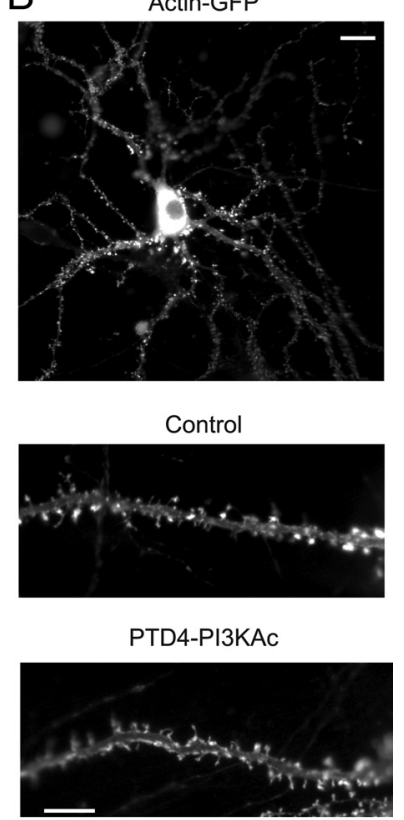

C

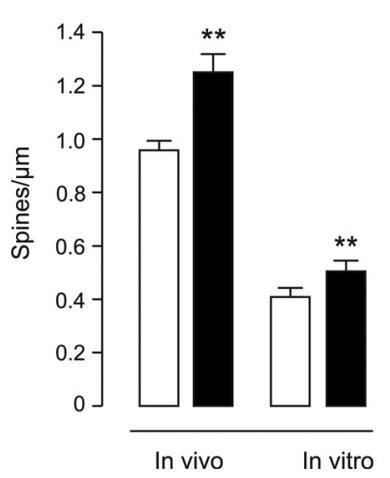

D

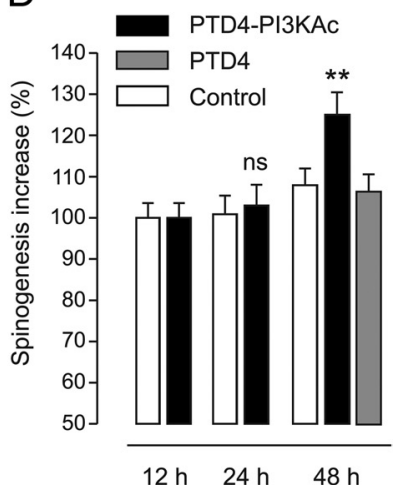

Figure 7. PI3Kactivation promotes spinogenesis in vivo and in vitro. $\boldsymbol{A}$, Confocal images from CA1 hippocampal neurons injected with Lucifer yellow. Top, Control animals. Bottom, PTD4PI3KAc-injected animals. Scale bar, $10 \mu \mathrm{m}$. B, Quantification of spine density changes in vitro in GFP-actin-transfected cultured neurons. Top, A representative picture of a GFP-actintransfected neuron showing intense staining concentrated on the dendritic spines. On day 19, hippocampal cultures were treated with either PTD4 (5 $\mu \mathrm{g} / \mathrm{ml})$ or PTD4-PI3KAc $(5 \mu \mathrm{g} / \mathrm{ml})$ for 48 h. Pictures show representative dendrites from hippocampal neurons in control (middle) and PTD4-PI3KAc-treated (bottom) cultures. Scale bar, $10 \mu \mathrm{m}$. C, Summary of the effects on spine density. Data represent the number of spines per micrometer of dendritic length. In vivo, mean spine density increased from $0.95 \pm 0.03$ spines $/ \mu \mathrm{m}$ in the controls to $1.25 \pm 0.06 \mathrm{spines} / \mu \mathrm{m}$ in treated animals (control: 2646 spines from 44 dendrites, five animals; treatment, 3050 spines from 38 dendrites, five animals). In vitro, spine density in control cultures was $0.42 \pm 0.01$ compared with $0.51 \pm 0.02$ after $48 \mathrm{~h}$ of treatment. The number of dendrites analyzed was 78 (702 spines) under control conditions and 78 ( 839 spines) from three different treated cultures. Statistically significant differences were found between control and treated groups. Student's $t$ test, $p=0.0059$ and $p=0.002$, respectively, for in vivo and in vitro. $\boldsymbol{D}$, In vitro spinogenesis time course. GFP-actin-transfected neurons ( $19 \mathrm{~d}$ in vitro) were treated with $5 \mu \mathrm{g} / \mathrm{ml}$ PTD4PI3KAc, the cells were processed, and the spines were quantified 12,24 , and $48 \mathrm{~h}$ later. Differences were only statistically different after $48 \mathrm{~h}$ (Student's $t$ test; $n=700$ spines from two different cultures). As expected, PTD4 alone failed to induce changes in spine density.

PI3K activation facilitates associative learning in parallel to its effect of increasing spine density.

\section{Discussion}

The data reported in this study demonstrate that PI3K signaling mediates synaptogenesis and spinogenesis in mammalian neu-
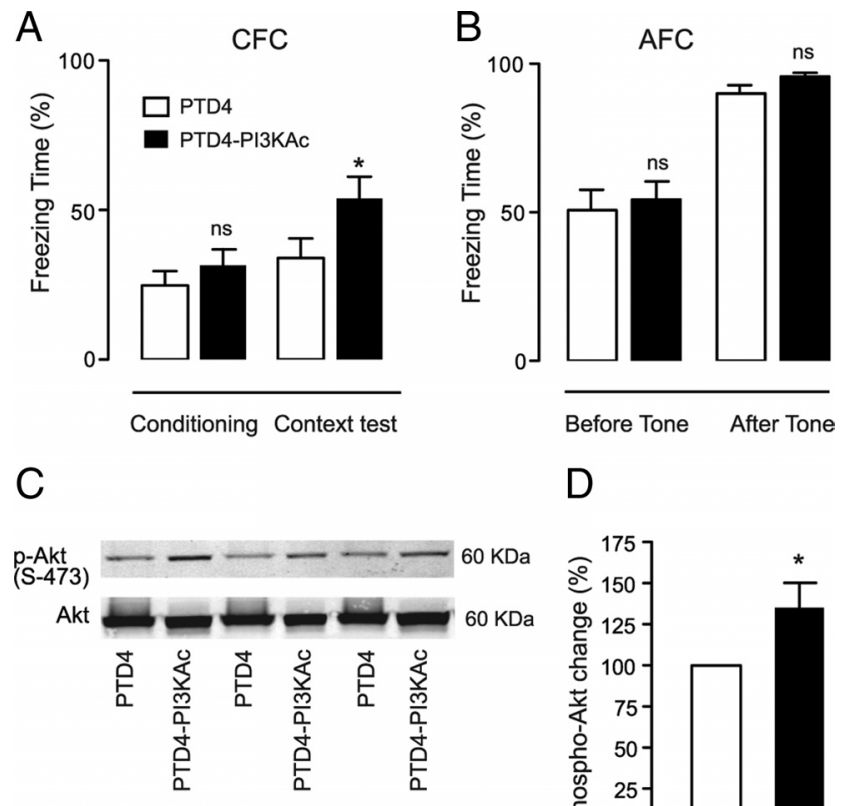

D

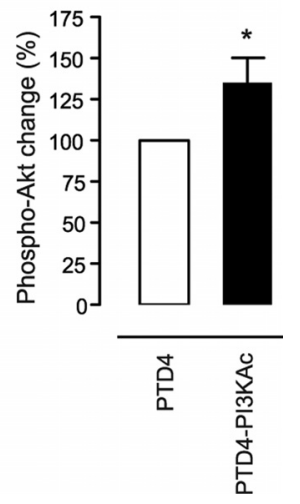

Figure 8. Fear conditioning. Animals were intracerebrally ventricularly injected with either $10 \mu \mathrm{g}$ of PTD4-PI3KAc (dark bars) or with the PTD4 transduction domain (open bars) $1 \mathrm{~d}$ before training. $A$, CFC: during training (i.e., conditioning), no differences in freezing values were observed between control and treated rats ( $n=10$ animals/group), either during the first 3 min of exploration or during the shock exposure phase (n.s.; Student's $t$ test, $p=0.35$ ), indicating normal fear acquisition and no differences in sensitivity to the shocks. Context test: $24 \mathrm{~h}$ later, PTD4-PI3KAc-treated rats showed higher freezing levels than control when re-exposed to the conditioning chambers with no shock delivery fear (Student's $t$ test, $p=0.036$ ). B, AFC: during testing (i.e., $1 \mathrm{~d}$ after conditioning), no differences in freezing values were observed between PTD4-PI3KAc-treated $(n=11)$ and control $(n=11)$ rats, either during the first $160 \mathrm{~s}$ (no tone) or during the 5 min of exposure to the conditioned tone (n.s; Student's $t$ test, $p=0.64$ and $p=0.124$ before and after the tone respectively). $C$, Representative Western blot showing the phospho-Akt levels $24 \mathrm{~h}$ after intracerebral ventricular injections. Results from hippocampal samples of three controls (PTD4) and three treated rats (PTD4-PI3KAc) are shown. D, In vivo Western blot quantification. On average, phospho-Akt levels were increased to $127.4 \pm 7.8 \%$ over the control injected brains ( $n=3$; Student's $t$ test, $p=0.033)$.

rons. This increase in synapse density is independent of changes in dendritic complexity and accompanied by an increase in synaptic release activity in cultured neurons. Furthermore, when the PI3K-activating peptide is injected in vivo, it enhances contextual fear memory in rats.

Regulation of PI3K activity was achieved by transduction of a peptide (PTD4-PI3KAc) mimicking a phosphorylated residue that binds to the $\mathrm{p} 85$ regulatory subunit of PI3K. Transduction peptides permit efficient delivery to all neurons and provide temporal control over PI3K activation (Wadia et al., 2004). Using this approach based on the interaction with the regulatory subunit construct, we have been able to maintain PI3K activation within physiological ranges and avoided several constraints associated with the overexpression of the catalytic subunits of PI3K or constitutively active Akt (Jaworski and Sheng, 2006).

The synaptogenic role of PI3K has been previously demonstrated in Drosophila (Martín-Peña et al., 2006). In this insect, PI3K overexpression leads to an approximately threefold increase in the number of synapses in both young and aged neurons. In the 
genetic approach used with flies, the PI3K catalytic domain (Dp110) was spatial and temporally overexpressed only in specific neurons by using the Gal4/UAS system (Brand and Perrimon, 1993). This genetic driving method strongly modifies the expression levels of active protein, thus generating a higher synaptogenic effect (Martín-Peña et al., 2006). Despite the differences in magnitude, our results clearly demonstrate that the synaptogenic pathway involving $\mathrm{PI} 3 \mathrm{~K}$ activation is conserved in mammals and has noticeable morphological and functional effects.

\section{Synaptogenesis and dendritogenesis are differentially modulated by PI3K}

Our results support a direct role of PI3K in regulating synaptogenesis. The PI3K-Akt signaling pathway has been implicated in morphogenesis and dendritic development (Rodgers and Theibert, 2002; Cosker and Eickholt, 2007). Targeted-membrane p1 10 overexpression dramatically increases overall dendritic length and complexity in young neurons, whereas no dendritic length changes have been observed in hippocampal mature neurons ( $>15$ d in culture) (Jaworski et al., 2005). Accordingly, in mature cultures from 2 to 3 weeks in vitro, we found that PI3K activation did not change dendritic complexity (Fig. 4). However, in cultures of the same age, PI3K activation was able to increase synaptic density by $40 \%$.

Axon polarization and elongation have been previously shown to be modulated by PI3K, and its local activation at the growth cone controls both processes through mPar3/mPar6 activation (Shi et al., 2003; Sosa et al., 2006). This PI3K effect prompted us to consider the possibility that an increase in axonal sprouting could partially explain our results, due to the formation of more synapses in the new axonal branches. The dendritic Sholl analysis could not completely rule out this possibility. However, several experimental observations allowed us to clarify this issue. First, if more axonal collaterals were formed due to PI3K overactivation, then synapse increase should be dependent on axonal density and, in such cases, high neuronal density would lead to higher synaptic increases. However, we observed no relationship between synaptic density and the percentage of increase after PI3K overactivation (Fig. 5). Second, PI3K activation in a fully developed in vivo system causes an increase in dendritic spines (Fig. 7). In this mature system, axonal extension is less likely to be responsible for the observed spine density increase. In summary, all the observations indicate that the synaptogenic effects of PI3K must be distinct from those that control dendritic growth in mammalian neurons.

\section{Synaptogenic elements of the PI3K signaling cascade}

The changes in synapse density are accompanied by an increase in the levels of the ubiquitous presynaptic protein synapsin, as well as those of the postsynaptic protein PSD95. The two structurally different Akt inhibitors we used greatly reduced synapsin levels (Fig. 6E). This inhibition abolished the synapsin increase elicited by PI3K overactivation, indicating that the synaptogenic effect of PI3K is mediated mainly by Akt activation (Fig. 6).

In contrast, PSD95 levels were unaffected by Akt inhibition. We propose that differences in protein turnover between presynaptic vesicular and postsynaptic components might explain this difference (Ehlers, 2003; Velho and Mello, 2008). A further comparative study on the average lifetime of these proteins should determine whether this hypothesis is correct.

Another key element of the PI3K cascade is mTOR. The PI3K pathway to mTOR is mediated by Akt, and results in the inhibition of tuberin and the activation of Rheb (a small GTPase ho- molog of Ras), which in turn stimulates mTOR (Ma and Blenis, 2009). We found that mTOR inhibition by rapamycin reduced synapsin expression and synaptic density (Fig. 6D-F), suggesting that a basal mTOR activity contributes to synaptogenesis. Moreover, the combination of rapamycin and PTD4-PI3KAc failed to inhibit the effects of PI3K activation. In fact, the percentage increase in synapsin levels induced by PTD4-PI3KAc with respect to the corresponding controls, rapamycin alone $(25 \%)$ or the vehicle alone (29\%), was very similar. Considering these and other experimental evidence from vertebrates and Drosophila (Martín-Peña et al., 2006), we suggest that the synaptogenic pathway depends on PI3K-Akt through an mTOR-independent mechanism, possibly involving other effectors not yet identified downstream from the Akt signaling.

\section{Spines}

The role of the PI3K/Akt pathway in mature neurons, in which specialized properties such as synapse number and polarity have already been established, has been poorly studied. The results of this study show that PI3K activation is able to induce supernumerary spines in culture and in vivo hippocampal neurons, suggesting that the actual pathway sustaining PI3K synaptogenesis also plays a role in regulating the density of spines. In addition, previous experiments using a conditional PTEN knockdown in the cerebral cortex and hippocampus of mice show an increase in phospho-Akt and mTOR/S6K, which resulted in increased spine density (Kwon et al., 2006).

Several downstream elements of the PI3K signaling cascade have been involved in the regulation of the Rho family of small GTPases; furthermore, the activation of Ras by PI3K has been shown to induce neuritic outgrowth in several neuronal cell lines (Nusser et al., 2002). The small GTPases Racl and Cdc42 are key regulators of actin-rich dendritic spine morphogenesis in neurons. The expression of a constitutively active form of Racl in Purkinje cells induces the growth of a large number of spines, even though they are reduced in size (Luo et al., 1996). Moreover, in hippocampal neurons, Racl activation promotes spine formation, while Rho activation prevents their formation (Tashiro et al., 2000). Therefore, a PI3K-dependent mechanism for the coordinated regulation of synaptogenesis and spinogenesis is plausible through the control of Rac1 activation. Experiments using specific Racl inhibitors will help to further investigate PI3Kdependent spine induction.

\section{New-born synapses are functional}

Despite the great variability among cultures, hippocampal neurons stimulated with PTD4-PI3KAc showed an increase in functional synapses, as indicated by the basal mEPSC frequency augmentation. This result is consistent with the role of PI3K in maintaining $\mathrm{PIP}_{3}$ levels at postsynaptic densities and controlling AMPA receptor turnover (Arendt et al., 2010). The increase in mEPSC frequency $(\sim 30 \%)$ was lower than expected, considering the number of new synapses as defined by morphological criteria. Several reasons could account for this difference; most of these new-born synapses may have a low probability of release or are indeed silent synapses (Hanse et al., 2009). Additional electrophysiological characterization of the calcium-evoked release will help to elucidate this issue.

Importantly, PI3K activation was found to affect cognitive behavior (Fig. 8). Contextual fear conditioning is mainly dependent on two limbic structures: the amygdala and the dorsal hippocampus, while auditory fear conditioning is amygdala (but not hippocampus) dependent (Selden et al., 1991; Kim and Fanselow, 
1992; Phillips and LeDoux, 1992; Lopez-Fernandez et al., 2007). Compared with control rats, animals injected intracerebrally ventricularly with PTD4-PI3KAc showed improved contextual (Fig. $8 A$ ), but not auditory (Fig. $8 B$ ) fear memory. These results support the view that, under our experimental conditions, the peptide is able to improve hippocampus-dependent memory.

These results fit in with the well documented role of PI3K in synaptic plasticity. PI3K activity is required for the expression, but not the induction, of long-term potentiation (LTP) in the hippocampal CA1 region (Sanna et al., 2002). Studies performed on the prefrontal cortex have demonstrated that LTP increases the levels of Akt, mTOR, p70S6K, and 4E-BP1 phosphorylation; conversely, the injection of PI3K or mTOR inhibitors suppressed LTP induction (Sui et al., 2008). The enhancement in learning ability presented here may result from a potentiation of synaptic plasticity due to PI3K overactivation or, over a longer period of time, it may be a direct effect of the increase in hippocampal spine density.

Together, this study shows that PI3K activation is a powerful tool to regulate the density of synapses and spines in vitro and in vivo, in young as well as in older mammalian neurons. More relevant, the treatment that activates PI3K also elicits contextual learning changes. On these grounds, the development of pharmacological tools based on the PI3K pathway may be of help in the treatment of neurological disorders that are clinically characterized by synaptic and neuronal loss in specific brain areas.

\section{References}

Arendt KL, Royo M, Fernández-Monreal M, Knafo S, Petrok CN, Martens JR, Esteban JA (2010) PIP $_{3}$ controls synaptic function by maintaining AMPA receptor clustering at the postsynaptic membrane. Nat Neurosci 13:36-44.

Ballesteros-Yáñez I, Benavides-Piccione R, Elston GN, Yuste R, DeFelipe J (2006) Density and morphology of dendritic spines in mouse neocortex. Neuroscience 138:403-409.

Banker G, Goslin K (1998) Culturing nerve cells. Cellular and molecular neuroscience series (Stevens CF, ed.). Cambridge, MA: MIT Press.

Barnett SF, Defeo-Jones D, Fu S, Hancock PJ, Haskell KM, Jones RE, Kahana JA, Kral AM, Leander K, Lee LL, Malinowski J, McAvoy EM, Nahas DD, Robinson RG, Huber HE (2005) Identification and characterization of pleckstrin-homology-domain-dependent and isoenzyme-specific Akt inhibitors. Biochem J 385:399-408.

Bekkers JM, Stevens CF (1989) NMDA and non-NMDA receptors are colocalized at individual excitatory synapses in cultured rat hippocampus. Nature 341:230-233.

Benavides-Piccione R, Ballesteros-Yáñez I, DeFelipe J, Yuste R (2002) Cortical area and species differences in dendritic spine morphology. J Neurocytol 31:337-346.

Benson DL, Watkins FH, Steward O, Banker G (1994) Characterization of GABAergic neurons in hippocampal cell cultures. J Neurocytol 23:279-295.

Brand AH, Perrimon N (1993) Targeted gene expression as a means of altering cell fates and generating dominant phenotypes. Development 118:401-415.

Brunet A, Datta SR, Greenberg ME (2001) Transcription-dependent andindependent control of neuronal survival by the PI3K-Akt signaling pathway. Curr Opin Neurobiol 11:297-305.

Cammalleri M, Lütjens R, Berton F, King AR, Simpson C, Francesconi W, Sanna PP (2003) Time-restricted role for dendritic activation of the mTOR-p70S6K pathway in the induction of late-phase long-term potentiation in the CA1. Proc Natl Acad Sci U S A 100:14368-14373.

Chun KH, Kosmeder JW 2nd, Sun S, Pezzuto JM, Lotan R, Hong WK, Lee HY (2003) Effects of deguelin on the phosphatidylinositol 3-kinase/Akt pathway and apoptosis in premalignant human bronchial epithelial cells. J Natl Cancer Inst 95:291-302.

Colicos MA, Collins BE, Sailor MJ, Goda Y (2001) (2001) Remodeling of synaptic actin induced by photoconductive stimulation. Cell 107:605616.
Cosker KE, Eickholt BJ (2007) Phosphoinositide 3-kinase signalling events controlling axonal morphogenesis. Biochem Soc Trans 35:207-210.

Derossi D, Williams EJ, Green PJ, Dunican DJ, Doherty P (1998) Stimulation of mitogenesis by a cell-permeable PI 3-kinase binding peptide. Biochem Biophys Res Commun 251:148-152.

Ehlers MD (2003) Activity level controls postsynaptic composition and signaling via the ubiquitin-proteasome system. Nat Neurosci 6:231-242.

Elston GN, DeFelipe J (2002) Spine distribution in cortical pyramidal cells: a common organizational principle across species. Prog Brain Res 136:109-133.

Elston GN, Rosa MG (1997) The occipitoparietal pathway of the macaque monkey: comparison of pyramidal cell morphology in layer III of functionally related cortical visual areas. Cereb Cortex 7:432-452.

Fischer M, Kaech S, Knutti D, Matus A (1998) Rapid actin-based plasticity in dendritic spines. Neuron 20:847-854.

Fletcher TL, De Camilli P, Banker G (1994) Synaptogenesis in hippocampal cultures: evidence indicating that axons and dendrites become competent to form synapses at different stages of neuronal development. J Neurosci 14:6695-6706.

Franco B, Bogdanik L, Bobinnec Y, Debec A, Bockaert J, Parmentier ML, Grau Y (2004) Shaggy, the homolog of glycogen synthase kinase 3, controls neuromuscular junction growth in Drosophila. J Neurosci 24:6573-6577.

Friedman HV, Bresler T, Garner CC, Ziv NE (2000) Assembly of new individual excitatory synapses: time course and temporal order of synaptic molecule recruitment. Neuron 27:57-69.

Griffin RJ, Moloney A, Kelliher M, Johnston JA, Ravid R, Dockery P, O'Connor R, O'Neill C (2005) Activation of Akt/PKB, increased phosphorylation of Akt substrates and loss and altered distribution of Akt and PTEN are features of Alzheimer's disease pathology. J Neurochem 93:105-117.

Hanse E, Taira T, Lauri S, Groc L (2009) Glutamate synapse in developing brain: an integrative perspective beyond the silent state. Trends Neurosci 32:532-537.

Hay N, Sonenberg N (2004) Upstream and downstream of mTOR. Genes Dev 18:1926-1945.

Ho A, Schwarze SR, Mermelstein SJ, Waksman G, Dowdy SF (2001) Synthetic protein transduction domains: enhanced transduction potential in vitro and in vivo. Cancer Res 61:474-477.

Humbert S, Bryson EA, Cordelières FP, Connors NC, Datta SR, Finkbeiner S, Greenberg ME, Saudou F (2002) The IGF-1/Akt pathway is neuroprotective in Huntington's disease and involves Huntingtin phosphorylation by Akt. Dev Cell 2:831-837.

Jaworski J, Sheng M (2006) The growing role of mTOR in neuronal development and plasticity. Mol Neurobiol 34:205-219.

Jaworski J, Spangler S, Seeburg DP, Hoogenraad CC, Sheng M (2005) Control of dendritic arborization by the phosphoinositide-3'-kinase-Aktmammalian target of rapamycin pathway. J Neurosci 25:11300-11312.

Jiang H, Rao Y (2005) Axon formation: fate versus growth. Nat Neurosci 8:544-546.

Jiang H, Guo W, Liang X, Rao Y (2005) Both the establishment and the maintenance of neuronal polarity require active mechanisms: critical roles of GSK-3beta and its upstream regulators. Cell 120:123-135.

Kaech S, Banker G (2006) Culturing hippocampal neurons. Nat Protoc 1:2406-2415.

Kim JJ, Fanselow MS (1992) Modality-specific retrograde amnesia of fear. Science 256:675-677.

Kneussel M, Betz H (2000) Receptors, gephyrin and gephyrin-associated proteins: novel insights into the assembly of inhibitory postsynaptic membrane specializations. J Physiol 525:1-9.

Kornau HC, Schenker LT, Kennedy MB, Seeburg PH (1995) Domain interaction between NMDA receptor subunits and the postsynaptic density protein PSD-95. Science 269:1737-1740.

Kwon CH, Luikart BW, Powell CM, Zhou J, Matheny SA, Zhang W, Li Y, Baker SJ, Parada LF (2006) Pten regulates neuronal arborization and social interaction in mice. Neuron 50:377-388.

Lin CH, Yeh SH, Lin CH, Lu KT, Leu TH, Chang WC, Gean PW (2001) A role for the PI-3 kinase signaling pathway in fear conditioning and synaptic plasticity in the amygdala. Neuron 31:841-851.

Lopez-Fernandez MA, Montaron MF, Varea E, Rougon G, Venero C, Abrous DN Sandi C (2007) Upregulation of polysialylated neural cell adhesion 
molecule in the dorsal hippocampus after contextual fear conditioning is involved in long-term memory formation. J Neurosci 27:4552-4561.

Luo L, Hensch TK, Ackerman L, Barbel S, Jan LY, Jan YN (1996) Differential effects of the Rac GTPase on Purkinje cell axons and dendritic trunks and spines. Nature 379:837-840.

Ma XM, Blenis J (2009) Molecular mechanism of mTOR mediate translational control. Nat Rev Mol Cell Biol 10:307-318.

Martín-Peña A, Acebes A, Rodríguez JR, Sorribes A, de Polavieja GG, Fernández-Fúnez P, Ferrús A (2006) Age-independent synaptogenesis by phosphoinositide 3 kinase. J Neurosci 26:10199-10208.

Morales M, Colicos MA, Goda Y (2000) Actin-dependent regulation of neurotransmitter release at central synapses. Neuron 27:539-550.

Nusser N, Gosmanova E, Zheng Y, Tigyi G (2002) Nerve growth factor signals through TrkA, phosphatidylinositol 3-kinase, and Rac1 to inactivate RhoA during the initiation of neuronal differentiation of PC12 cells. J Biol Chem 277:35840-35846.

Opazo P, Watabe AM, Grant SG, O’Dell TJ (2003) Phosphatidylinositol 3-kinase regulates the induction of long-term potentiation through extracellular signal-related kinase-independent mechanisms. J Neurosci 23: 3679-3688.

Paxinos G, Watson C (1998) The rat brain in stereotaxic coordinates, Ed 4. San Diego, CA: Academic.

Phillips RG, LeDoux JE (1992) Differential contribution of amygdala and hippocampus to cued and contextual fear conditioning. Behav Neurosci 106:274-285.

Rao A, Kim E, Sheng M, Craig AM (1998) Heterogeneity in the molecular composition of excitatory postsynaptic sites during development of hippocampal neurons in culture. J Neurosci 18:1217-1229.

Rodgers EE, Theibert AB (2002) Functions of PI 3-kinase in development of nervous system. Int J Dev Neurosci 20:187-197.

Ruggero D, Sonenberg N (2005) The Akt of translational control. Oncogene 24:7426-7434.

Ruiz-Marcos A, Valverde F (1969) The temporal evolution of the distribution of dendritic spines in the visual cortex of normal and dark raised mice. Exp Brain Res 8:284-294.

Sanna PP, Cammalleri M, Berton F, Simpson C, Lutjens R, Bloom FE, Francesconi W (2002) Phosphatidylinositol 3-kinase is required for the expression but not for the induction or the maintenance of long-term potentiation in the hippocampal CA1 region. J Neurosci 22:3359-3365.

Segal M (2005) Dendritic spines and long term plasticity. Nat Rev Neurosci $6: 277-284$.

Selden NR, Everitt BJ, Jarrard LE, Robbins TW (1991) Complementary roles for the amygdala and hippocampus in aversive conditioning to explicit and contextual cues. Neuroscience 42:335-350.

Shapira M, Zhai RG, Dresbach T, Bresler T, Torres VI, Gundelfinger ED, Ziv NE, Garner CC (2003) Unitary assembly of presynaptic active zones from Piccolo-Bassoon transport vesicles. Neuron 38:237-252.

Shi SH, Jan LY, Jan YN (2003) Hippocampal neuronal polarity specified by spatially localized mPar3/mPar6 and PI 3-kinase activity. Cell 112:63-75.
Sholl DA (1953) Dendritic organization in the neurons of the visual and motor cortices of the cat. J Anat 87:387-406.

Sosa L, Dupraz S, Laurino L, Bollati F, Bisbal M, Cáceres A, Pfenninger KH, Quiroga S (2006) IGF-1 receptor is essential for the establishment of hippocampal neuronal polarity. Nat Neurosci 9:993-995.

Sudhof TC (2004) The synaptic vesicle cycle. Annu Rev Neurosci 27:509-547.

Sui L, Wang J, Li BM (2008) Role of the phosphoinositide 3-kinase-Aktmammalian target of the rapamycin signaling pathway in long-term potentiation and trace fear conditioning memory in rat medial prefrontal cortex. Learn Mem 15:762-776.

Tang SJ, Reis G, Kang H, Gingras AC, Sonenberg N, Schuman EM (2002) A rapamycin-sensitive signaling pathway contributes to long-term synaptic plasticity in the hippocampus. Proc Natl Acad Sci U S A 99:467-472.

Tashiro A, Minden A, Yuste R (2000) Regulation of dendritic spine morphology by the rho family of small GTPases: antagonistic roles of Rac and Rho. Cereb Cortex 10:927-938.

Tsokas P, Grace EA, Chan P, Ma T, Sealfon SC, Iyengar R, Landau EM, Blitzer RD (2005) Local protein synthesis mediates a rapid increase in dendritic elongation factor 1A after induction of late long-term potentiation. J Neurosci 25:5833-5843.

van den Pol AN, Obrietan K, Belousov AB, Yang Y, Heller HC (1998) Early synaptogenesis in vitro: role of axon target distance. J Comp Neurol 399:541-560.

Vanhaesebroeck B, Leevers SJ, Ahmadi K, Timms J, Katso R, Driscoll PC, Woscholski R, Parker PJ, Waterfield MD (2001) Synthesis and function of 3-phosphorylated inositol lipids. Annu Rev Biochem 70:535-602.

Velho TA, Mello CV (2008) Synapsins are late activity-induced genes regulated by birdsong. J Neurosci 28:11871-11882.

Wadia JS, Stan RV, Dowdy SF (2004) Transducible TAT-HA fusogenic peptide enhances escape of TAT-fusion proteins after lipid raft macropinocytosis. Nat Med 10:310-315.

Wymann MP, Pirola L (1998) Structure and function of phosphoinositide 3-kinases. Biochim Biophys Acta 1436:127-150.

Yoshimura T, Arimura N, Kawano Y, Kawabata S, Wang S, Kaibuchi K (2006) Ras regulates neuronal polarity via the PI3-kinase/Akt/GSK-3beta/ CRMP-2 pathway. Biochem Biophys Res Commun 340:62-68.

Yu J, Zhang Y, McIlroy J, Rordorf-Nikolic T, Orr GA, Backer JM (1998) Regulation of the p85/p110 phosphatidylinositol 3'-kinase: stabilization and inhibition of the p110alpha catalytic subunit by the p 85 regulatory subunit. Mol Cell Biol 18:1379-1387.

Yuste R, Bonhoeffer T (2004) Genesis of dendritic spines: insights from ultrastructural and imaging studies. Nat Rev Neurosci 5:24-34.

Ziv NE, Garner CC (2001) Principles of glutamatergic synapse formation: seeing the forest for the trees. Curr Opin Neurobiol 11:536-543.

Ziv NE, Garner CC (2004) Cellular and molecular mechanisms of presynaptic assembly. Nat Rev Neurosci 5:385-399. 